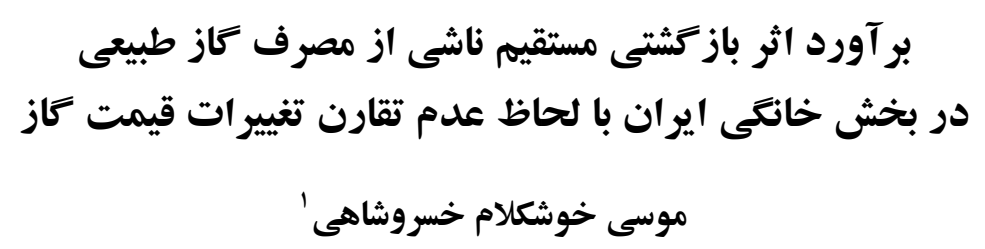

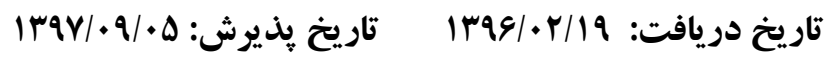

با توجه به اينكه بهبود كارائى مصرف انرزى و اثر باز گشتى ناشى از آن در ادبيات اقتصاد

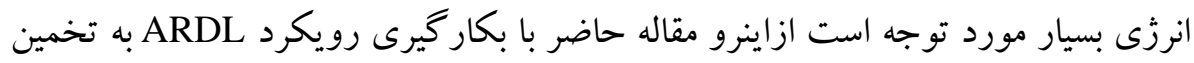

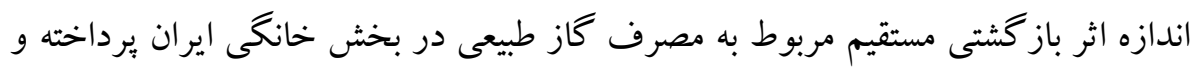
براى اين منظور از دادههاى دوره زمانى هوس|-هQ

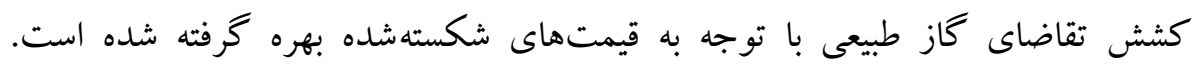

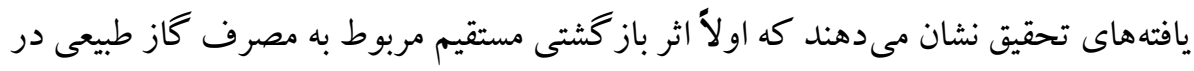
بخش خانكى كشور وجود داشته و در نتيجه صرفهجويى انرزى ناشى از بهبود كارائى

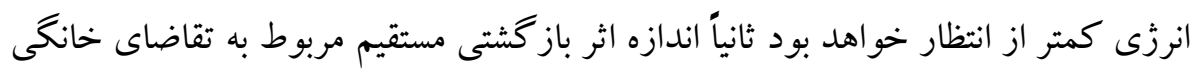

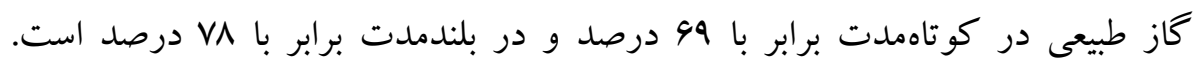

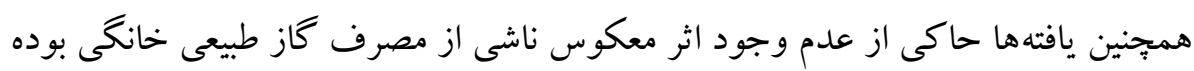

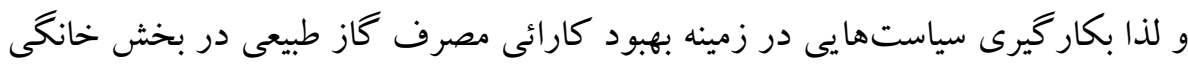
ايران قابل توصيه است.

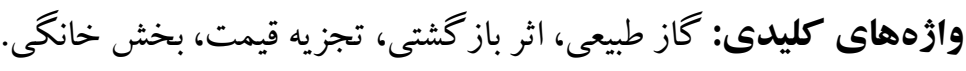

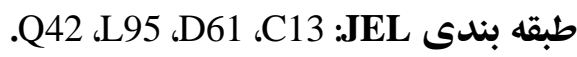

إ. استاديار دانشكده علوم اجتماعى و اقتصادى، دانشكاه الزهرا Email:m.khosroshahi@alzahra.ac.ir 
1. مقدمله

امروزه در اقتصاد جهانى، انرزى از نقش حائز اهميتى برخوردار است بطوريكه بدون

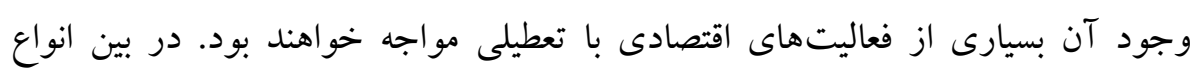

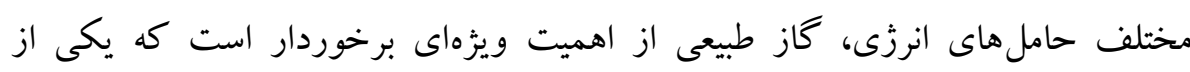

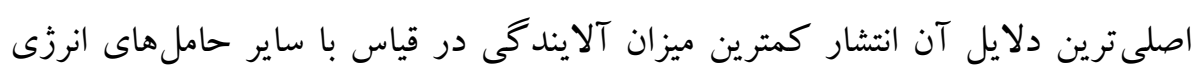

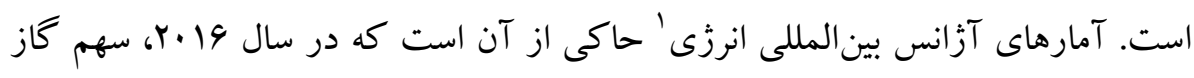

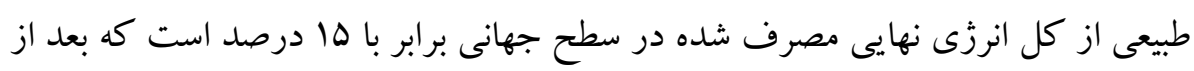

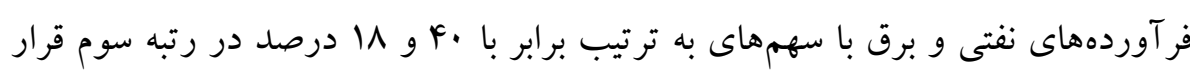

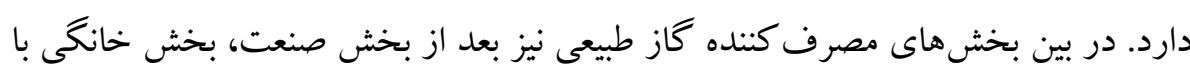

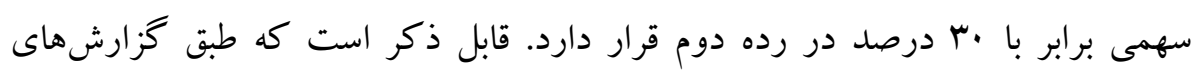

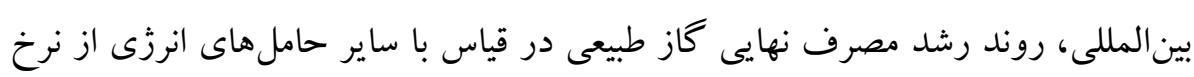
فزاينده ترى برخوردار بوده و رفته رفته سهم كاز طبيعى از مصرف نهايى حامل هاى انرزي

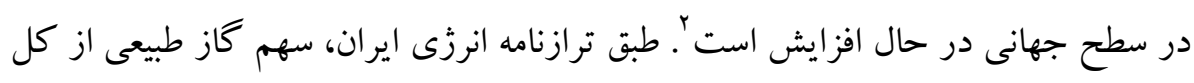

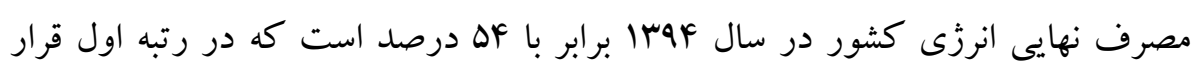

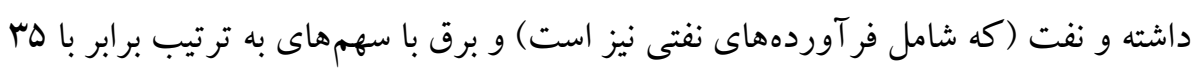
و · إدرصد در ردههاى بعدى قرار دارند.

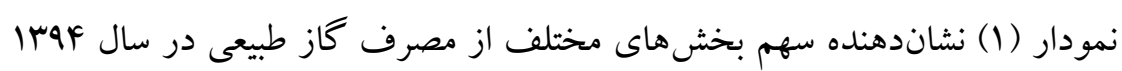

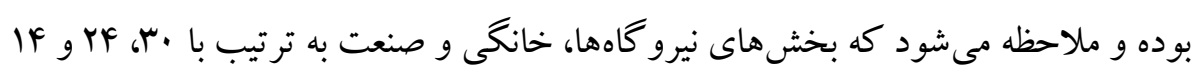

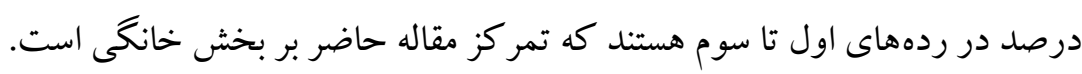




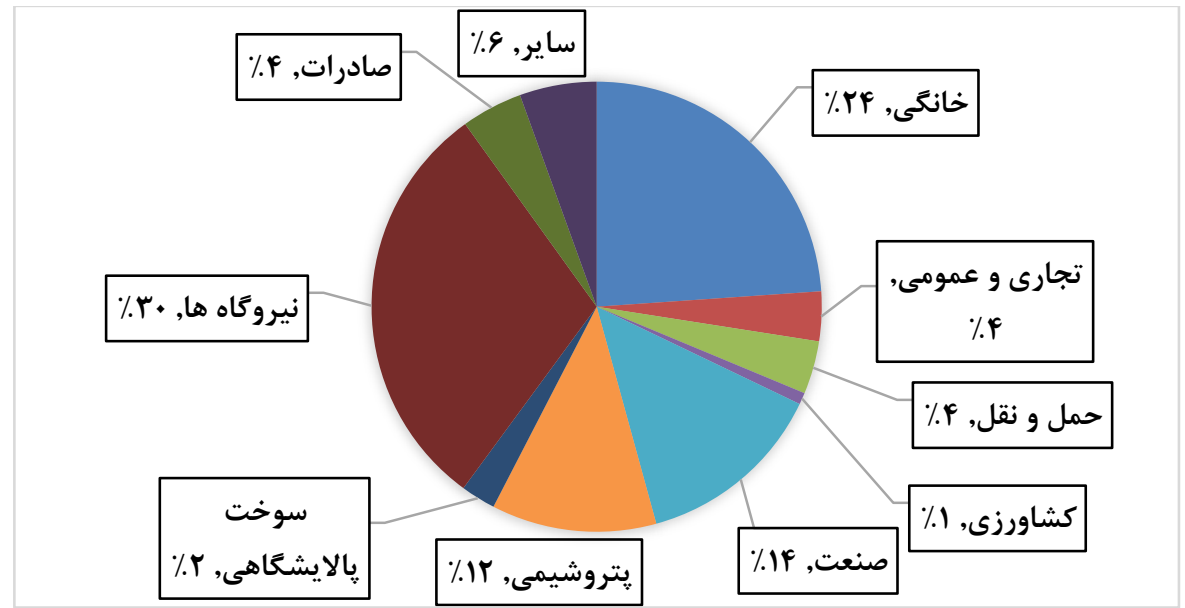

نمودار ا. سهم بخشهاى مختلف از مصرف كاز طبيعى در سال وجاجا (درصد)

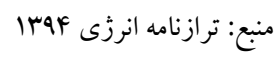

با توجه به اينكه مبادى اصلى مصرف گاز طبيعى شامل صادرات گاز طبيعى، تزريق

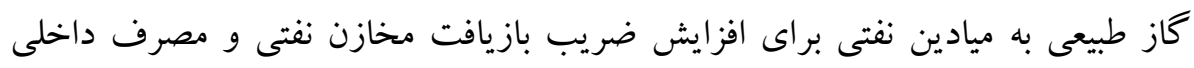

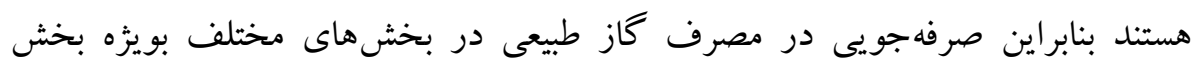

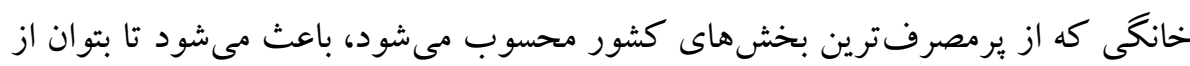

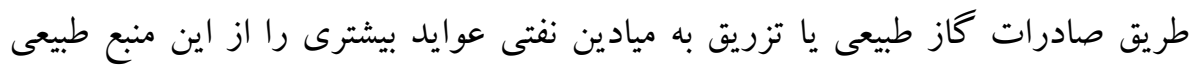

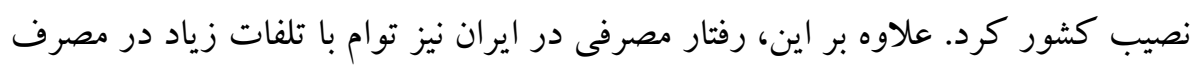

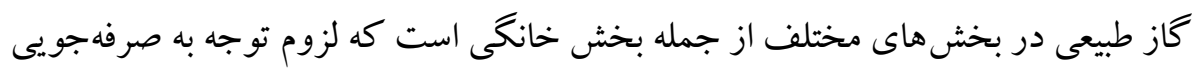

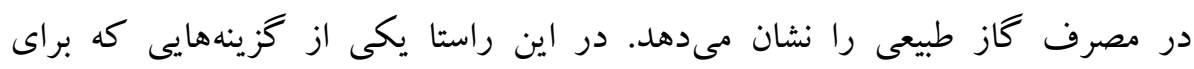

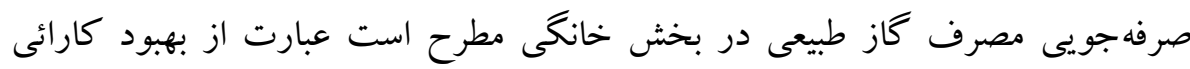

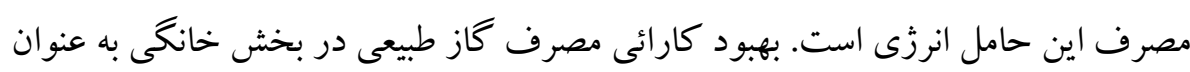
يكك استراتزى موثر در كاهش تقاضاى كاز مطرح بوده اما افزايش در كارائى لزوماً منجر به أنه

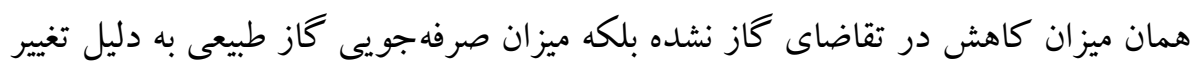
نكرش و رفتار مصرف كنند گان تضعيف مى شود كه اصطلاحاً اثر باز گشتى ' رخ مىدهد. 
اثر باز گشتى نشاندهنده واكنش رفتارى و نگگشى به بهبود كارائى انرزى بوده و لذا ميزان

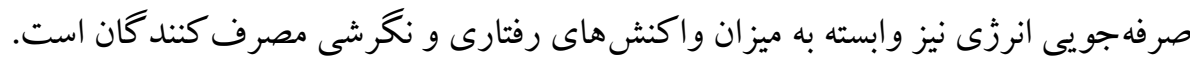

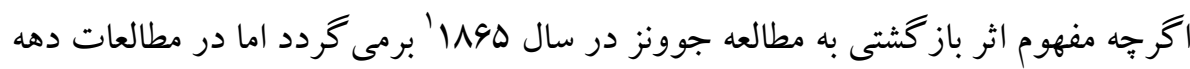

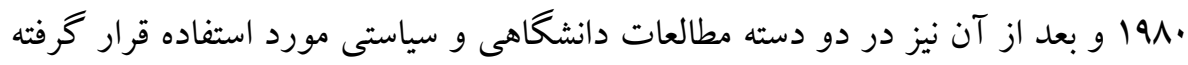

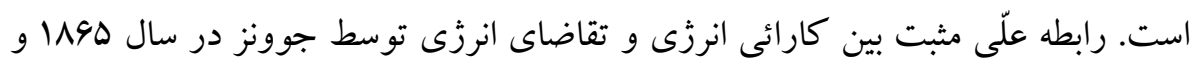

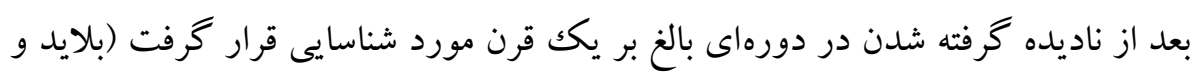

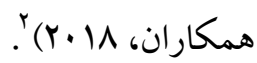

تمركز اين مقاله بر اثر باز گتى مستقيم مربوط به مصرف گاز طبيعى در بخش خانكى ايران بوده و فرضيه اصلى اين است كه عوامل مختلفى بر نكرش و و رفتار خانو ارها

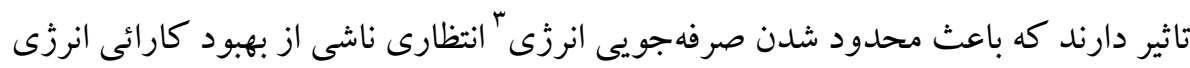
مى شود. نو آورى هاى مقاله حاضر نسبت به مطالعات قبلى عبارتند از اينكه (اولاً) مقدار اثر

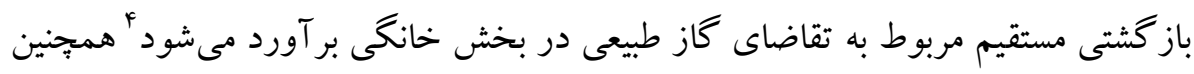

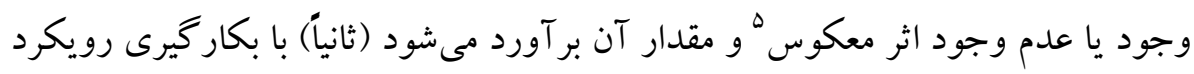

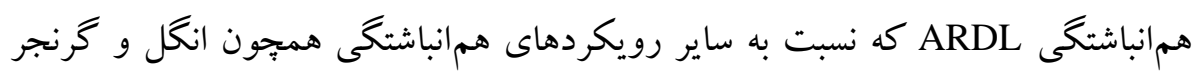

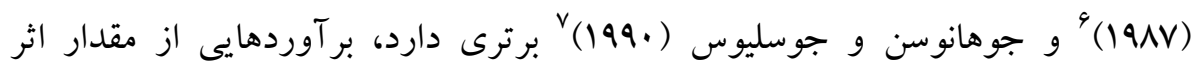

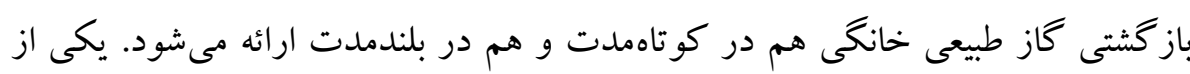

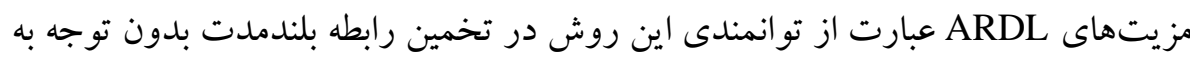
I(1) بودن I(0)

1. Jevons, 1865

2. Belaid et. al. (2018)

"rergy Conservation يا صرفه جويى انرزى عبارت از مجموعه اقداماتى است كه مصرف كنند كان انرزى انجام مىدهند تا مصرف انرزى كاهش يابد.

5. Backfire Effect

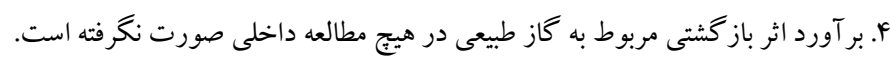

6. Engle and Granger, 1987

7. Johansen and Juselius, 1990 
نسبت به افزايش يا كاهش در قيمت انرزى واكنش همسانى ندارد لذا تلاش شده است تا از طريق تجزيه قيمت كاز طبيعى و بر آورد كشش قيمتى مربوط به كاهش قيمت كارئ كاز طبيعى، بر آورد دقيق ترى از اثر باز گشتى ارائه كردد.

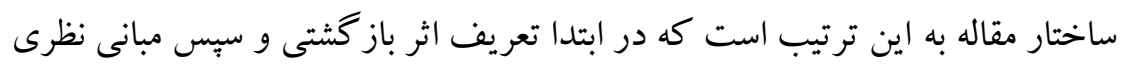
و روش اندازه گيرى آن آورده شده است. در ادامه ضمن تبيين بيشينه تحقيق، نحوه كردآورى دادها مورد اشاره قرار گرفتهاند. تصريح مدل تشكيل دهنده بخش اند بعدى أندى مقاله

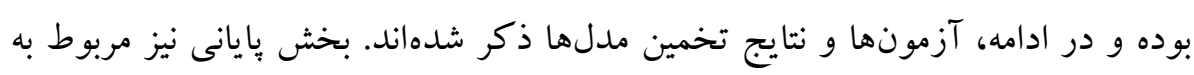
نتيجه گيرى و توصيه سياستى است.

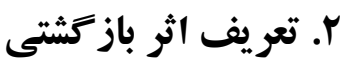

يكى از مفاهيم مهم در ادبيات اقتصاد انرزى، اثر باز گشتى است. اثر باز گثتى به اين معنى

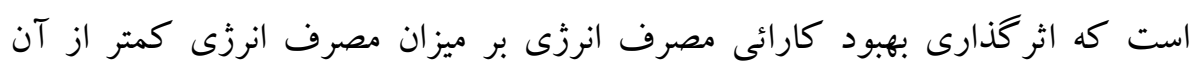
مقدارى است كه (قبل از بهبود كارايى مصرف انرزى) انتظار مىرفت (خوشكلام

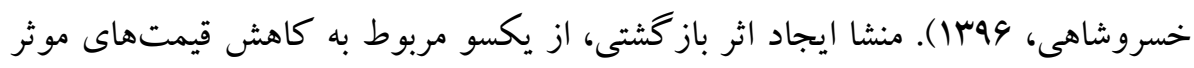

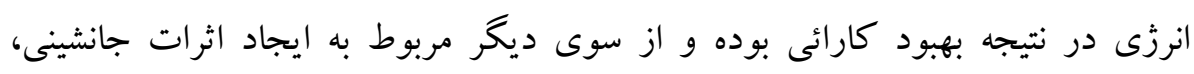

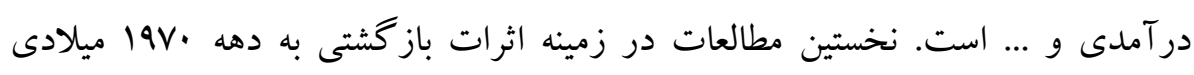
برمى گردد اما در دهه هاى بعد بحث اثرات باز گشتى بطور گستردهترى مورد بررسى قرار

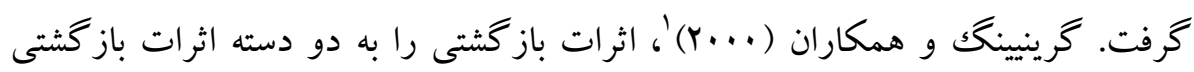

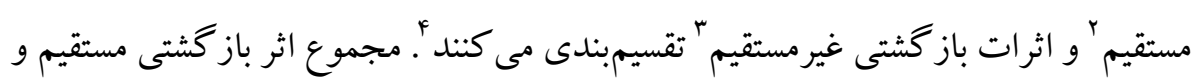

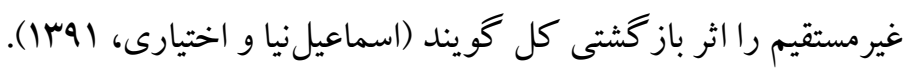

1. Greening et. al. (2000)

2. Direct rebound effect

3. Indirect Rebound Effect

F. اثرات باز گشتى هم در مورد مصرف كنند كان كالاها و خدمات (Consumers) و هم در مورد توليدكند كان كالاها و خدمات (Producers) به دو دسته مستقيم و غيرمستقيم تقسيم بندى مى شود كه در مقاله حاضر از نغاء

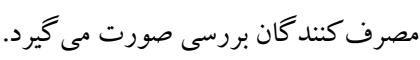


اثر باز گتنى مستقيم اثرى است كه به خدمات انرزى مربوط بوده و به انرزىاى كه

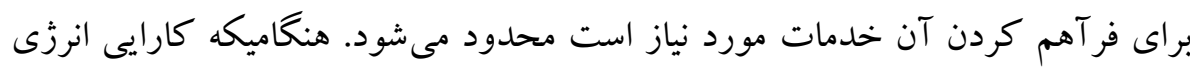
بهبود مىيابد، قيمت خدمات انرزى كاهش يافته و در نتيجه تقاضا براى خدمات انرزى افزايش مى يابد. اين مسئله موجب بوجود آمدن اثر جانشينى در بكار گيرى بيشتر آن دسته

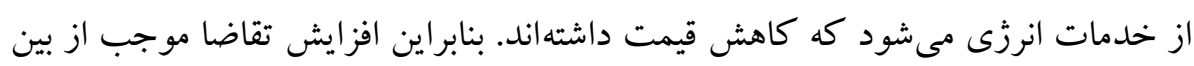

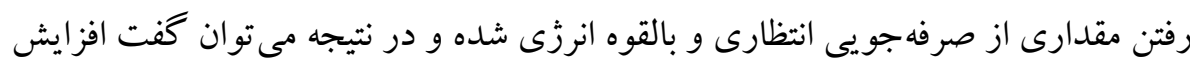
كارايى انرزى بطور مستقيم و از طريق افزايش مصرف انرزى منجر به از بين رفتن مقدارى

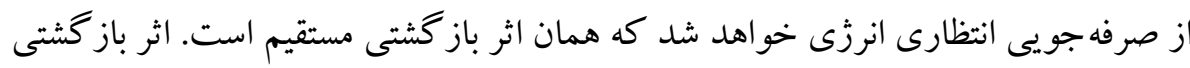

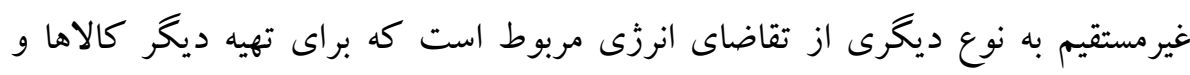

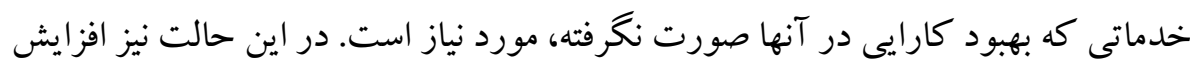
مصرف كالاها و خدمات ناشى از بهبود كارايى انرزى است بدين ترتيب كه وقتى با

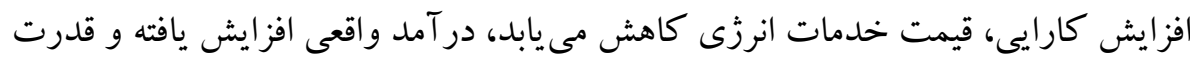

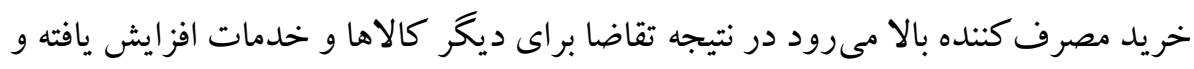

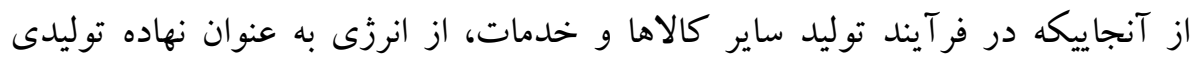

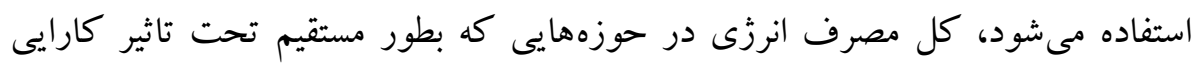

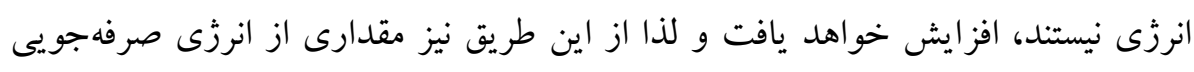

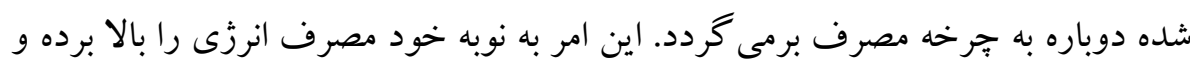

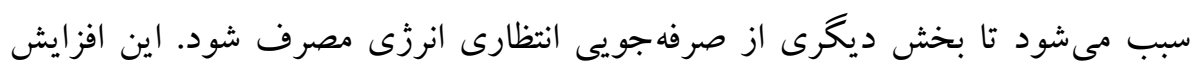

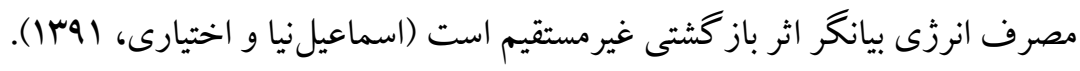




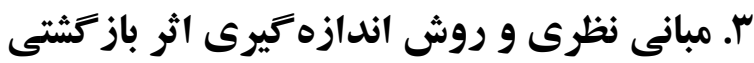

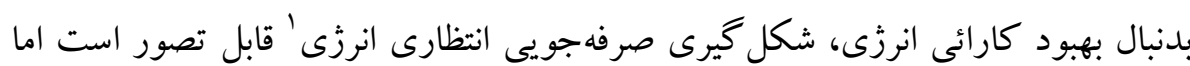

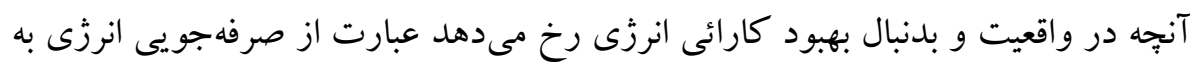

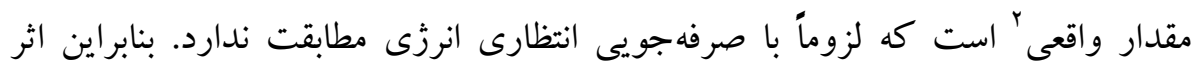
باز كشتى را مىتوان به كمك رابطه 100 *xpected

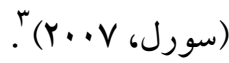

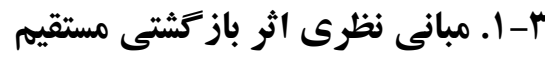
با فرض اينكه مصرف كند كان حدا كثر كننده مطلوبيت داراى رفتارى عقلايى بوده و دارئي

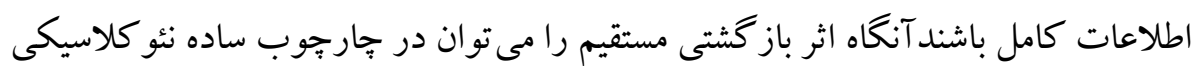

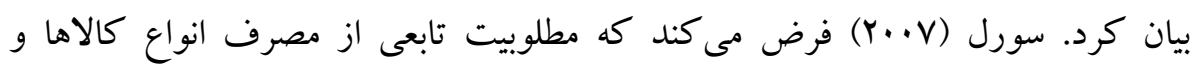

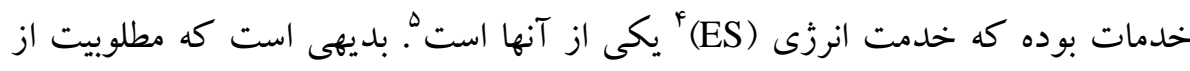

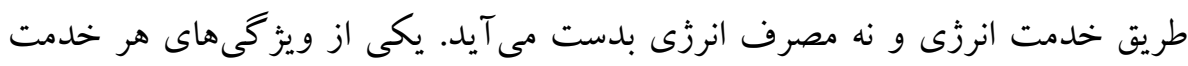
انززى عبارت از كار مفيد (S)

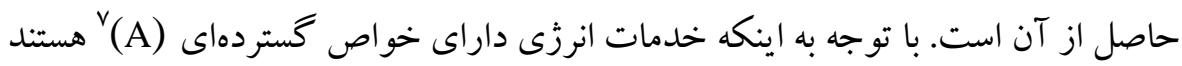

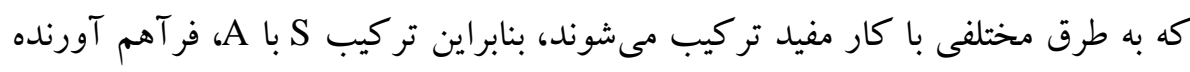
خدمت كاملى از انرزى هستند (ES=f(S,A).

1. Expected Energy Saving

2. Actual Energy Saving

3. Sorrell (2007)

4. Energy Service

هـ خدمت انرزّى (مثل گرمايش) از تركيب انرزّى (مثل كاز طبيعى) با وسايل تبديل كننده انرزى به كار مفيد (مثل بخارى كازى) حاصل مى شود.

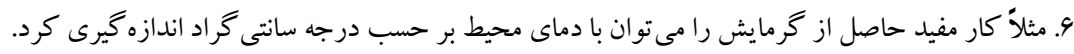

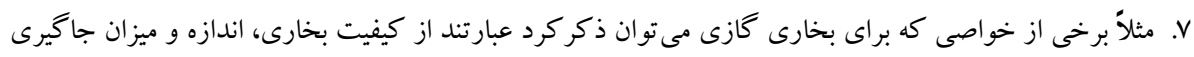

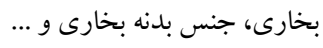


كارائى انرزى ( ع) از نسبت كار مفيد به نهاده انرزى حاصل مىشود ( $P_{S}=\frac{P_{E}}{\varepsilon}$ قيمت كار مفيد (P) كه كاهاً قيمت موثر انرزى نيز ناميده مى شود عبارت أن

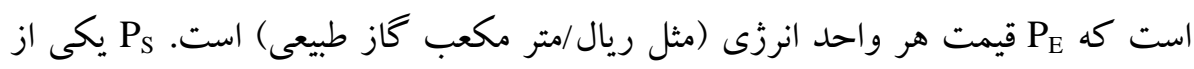
اجزاى هزينه كل كار مفيد (P) است. ساير اجزاء شامل هزينهاى سرمايهاى ساليانه،

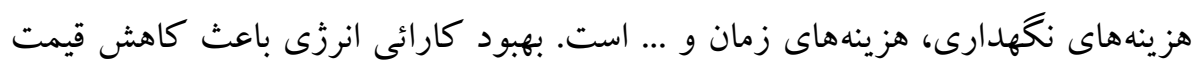
موثر انرزى مىشود. البته با توجه به اينكه كاهش قيمت موثر انرزى مى تواند ساير هزينها

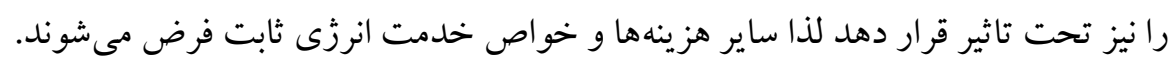

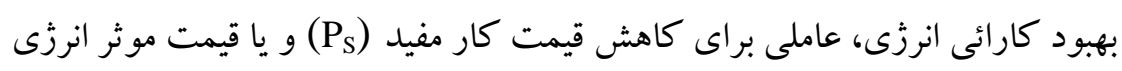

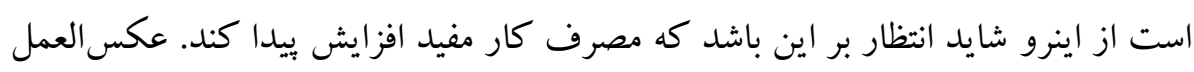
به اين كاهش در قيمت موثر انرزى را مى توان بصورت نمودارى و با استفاده از منحنىهاى

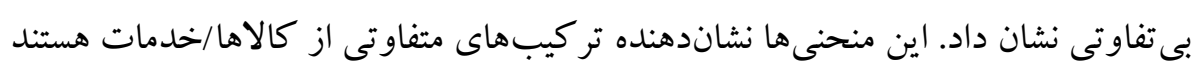

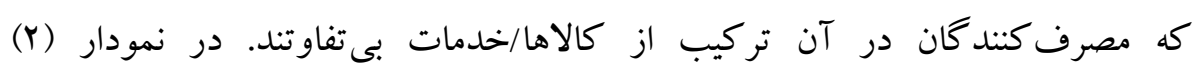

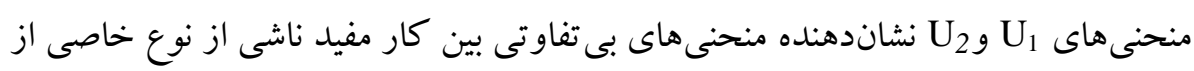

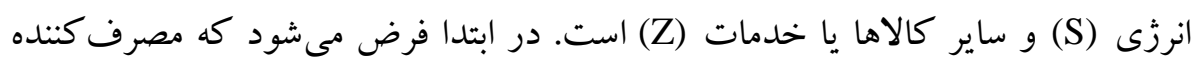

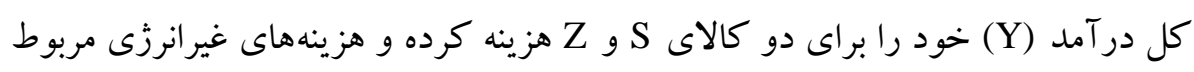
به خدمت انرزى صفر باشد. خط نشاندهنده قيمت كار مفيد و $P_{S}$ معادله قيد بودجه را مىتوان بصورت $Y \geq P_{S} S_{0}+P_{Z} Z_{0}$ نوشت كه شيب قيد بودجه نيز برابر با Pمك است 


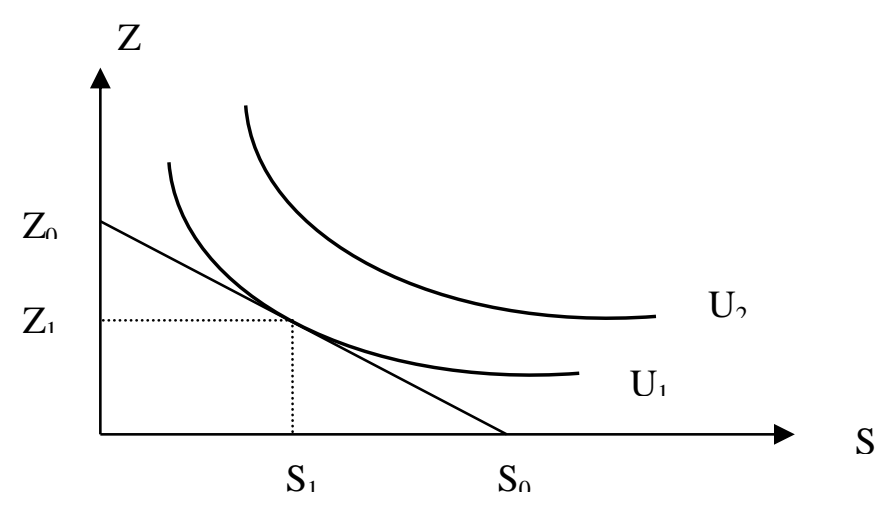

نمودار r. تبادل بين مصرف كار مفيد و مصرف ساير كالاها

$$
\text { منبع: سورل (r..v) }
$$

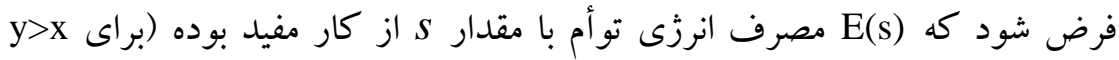

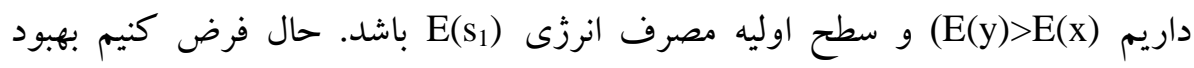

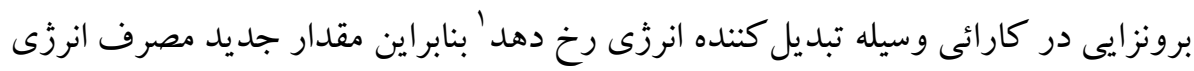

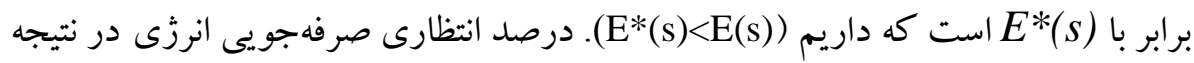

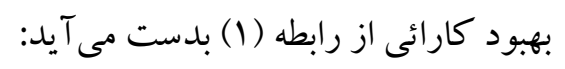
Expected $=\frac{E\left(s_{1}\right)-E^{*}\left(s_{1}\right)}{E\left(s_{1}\right)} \times 100 \%$

در اين رابطه، درصد صرفهويى انرزى بيش از درصد واقعى صرفهويى انرزى بر آورد شده است زيرا فرض شده كه بدنبال بهبود كارائى انرزى، كار مفيد (s) بدون تغيير

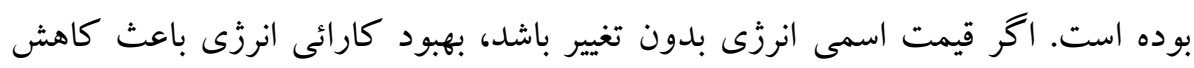
قيمت موثر انرزى شده (

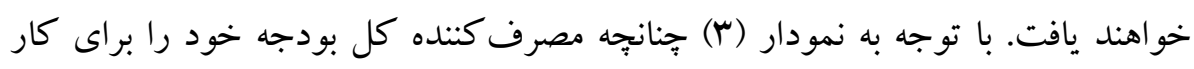
مفيد هزينه كند، قادر به مصرف مقدار بيشترى (

ا. قابل ذكر است كه بهبود كارائى بدون در نظر گرفتن هزينهاى مربوط به آن است. به عبارت ديخر، بهبود كارائى

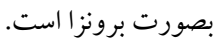


خط بودجه از مصرف كننده افزايش يافته در حاليكه درآمد اسمى وى بدون تغيير مانده است. تركيب بهينه مصرف در نقطه بى تفاوتى U2 (كه نشاندهنده بيشترين مقدار مطلوبيتى است كه مى توانست از سطح جديد

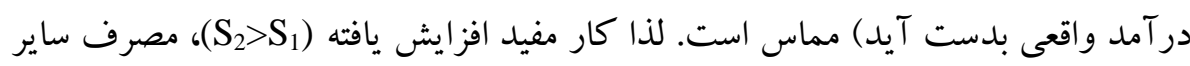
كالاها و خدمات كاهش يافته $\left(Z_{2}<Z_{1}\right)($ و مصرف كننده سطح بالاترى از مطلوبيت (ا بدست آورده است. $\left(\mathrm{U}_{2}>\mathrm{U}_{1}\right)$

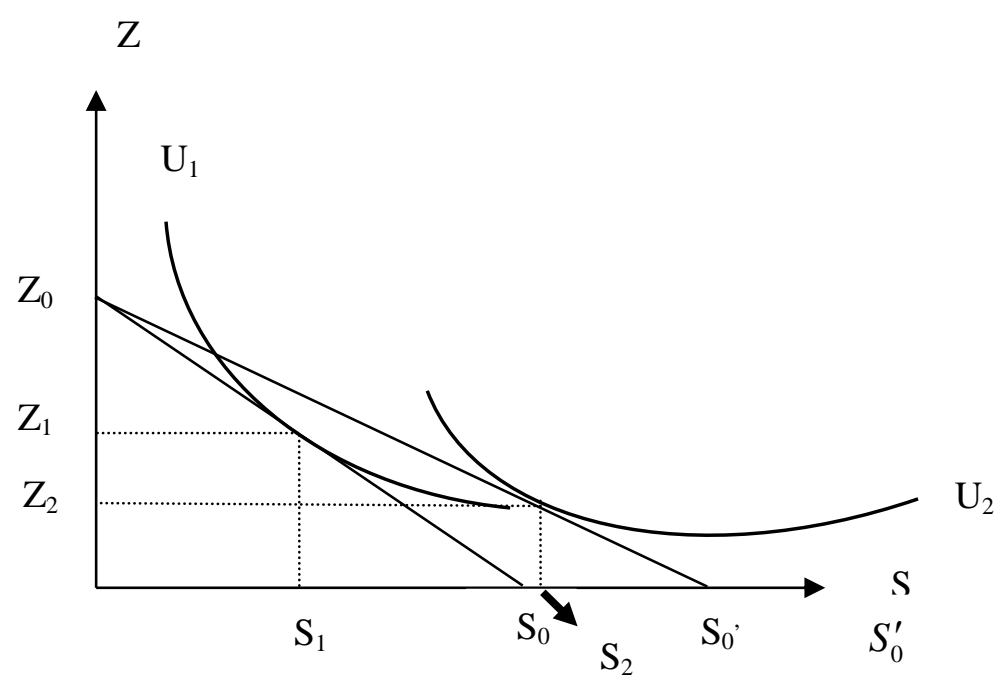
نمودارسّ. تغيير مصرف بدنبال بهبود كارائى انرخى

$$
\text { منبع: سورل (r..v) }
$$$$
\text { درصد واقعى صرفهجويى انرزى بصورت رابطه (Y) محاسبه مى شود: }
$$

Actual $=\frac{E\left(s_{1}\right)-E^{*}\left(s_{2}\right)}{E\left(s_{1}\right)} \times 100 \%$

بديهى است كه مصرف انرزى به ازاى هر واحد كار مفيد، كاهش يافته ( (

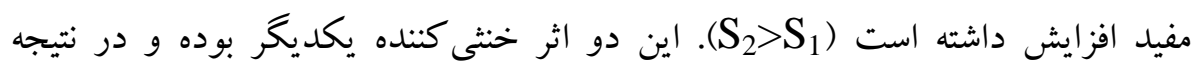


علامت Actual مبهم است: بهبود كارائى انرزى شايد باعث افزايش و شايد باعث كاهش

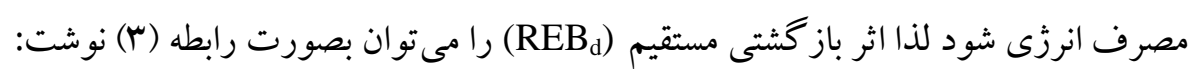

$$
R E B_{d}=\frac{\text { Expected }- \text { Actual }}{\text { Expected }} \times 100 \%
$$

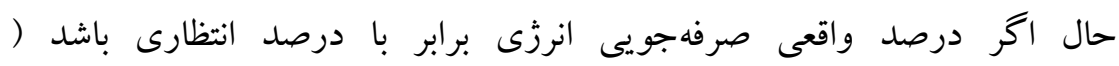

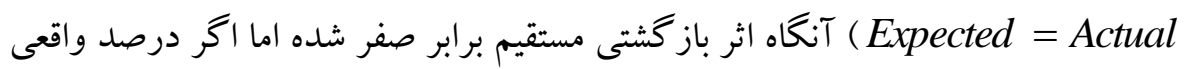

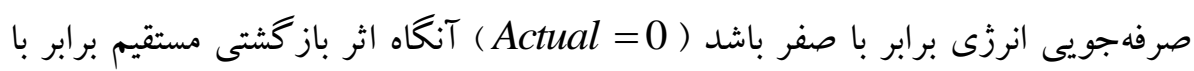

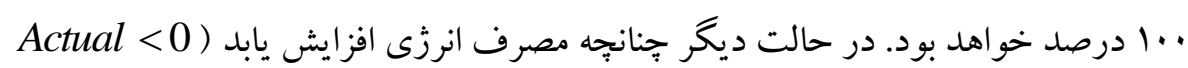

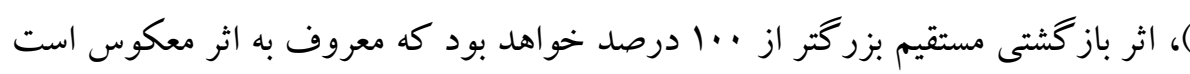

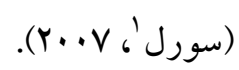

$$
\begin{aligned}
& R E B_{d}=\frac{\left(E\left(s_{1}\right)-E^{*}\left(s_{1}\right)\right)-\left(E\left(s_{1}\right)-E^{*}\left(s_{2}\right)\right)}{E\left(s_{1}\right)-E^{*}\left(s_{1}\right)} \times 100 \% \\
& R E B_{d}=\frac{E^{*}\left(s_{2}\right)-E^{*}\left(s_{1}\right)}{E\left(s_{1}\right)-E^{*}\left(s_{1}\right)} \times 100 \%
\end{aligned}
$$

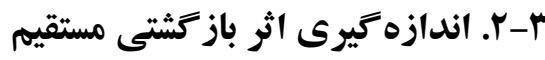

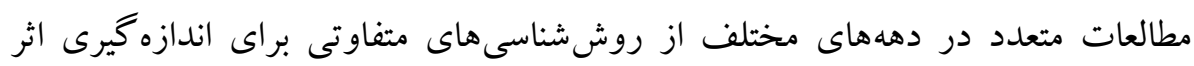

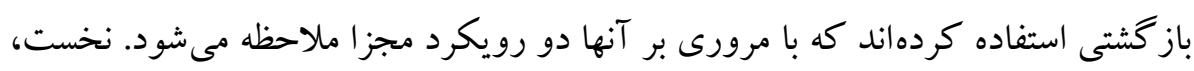

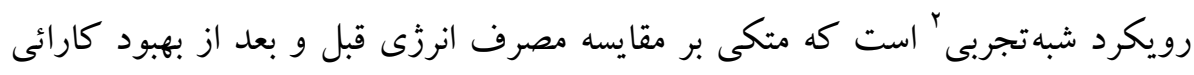
بوده و به در دسترس بودن دادههاى دقيق و متغيرهاى كنترل وابسته است. رويكرد دوم

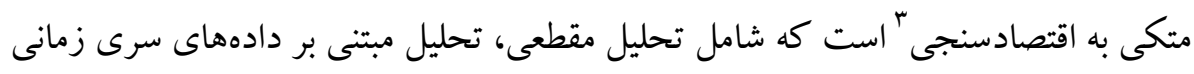

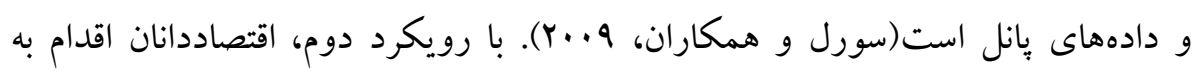
ارزيابى كشش كارائى خدمت انرزى (حساسيت تقاضاى خدمت انرزى به بهبود كارائى

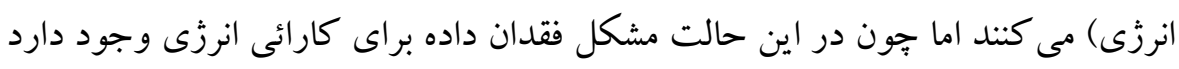

1. Sorrell

2. Quasi-Experimental Approach

3. Econometric Approach 
لذا از كشش قيمتى خدمت انرزى استفاده مى شود كه مقاله حاضر نيز متمركز بر اين روش

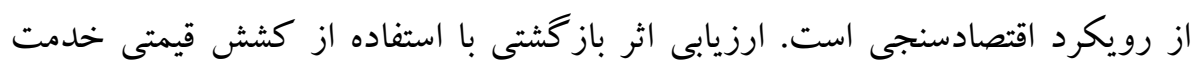
انرزى در بسيارى از مطالعات بكار گرفته شده است.

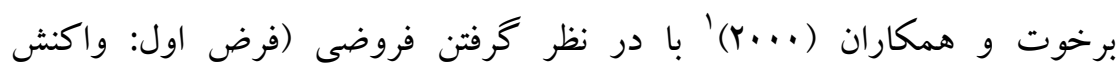
مصرف كنندكان به بهبود كارائى انرزى و كاهش در قيمت انرزى مشابه است. فرض دوم:

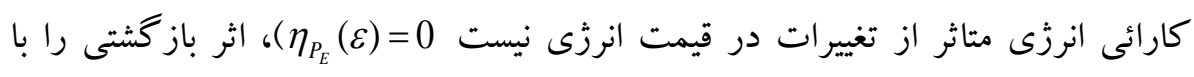

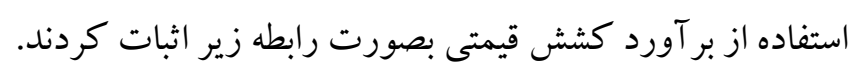
$\eta_{\varepsilon}(E)=-\eta_{P_{S}}(S)-1$

در اين رابطه، (E) خدمت انرزى نسبت به قيمت خدمت انرزى (

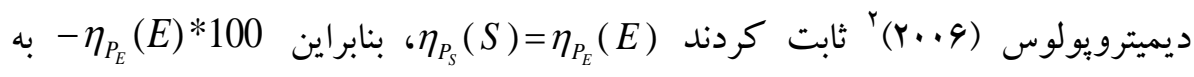
عنوان اندازه اثر باز گشتى مىباشد كه (E)

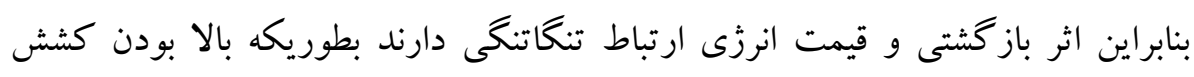

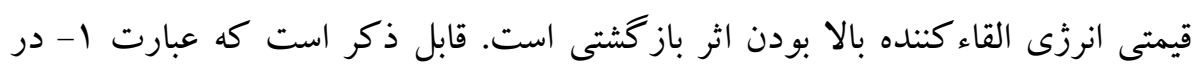
انتهاى رابطه (9) متناظر با يتانسيل صرفه جويى انرزى است. يكى از مشكلات روش فوقالذكر اين است كه كشش قيمتى انرزى نسبت به افزايش

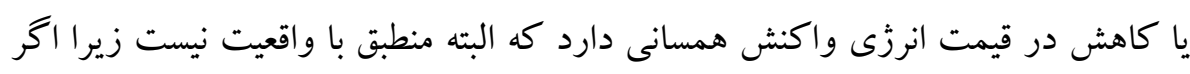

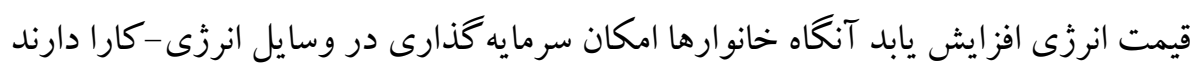

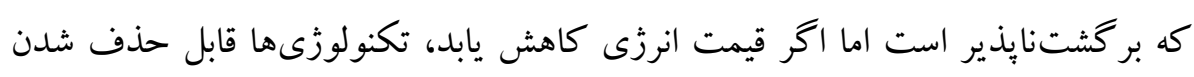

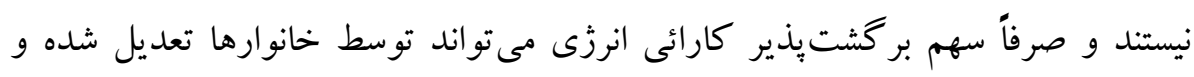
افز ايش يابد كه شكلدهنده اثر باز خشتى است.

1. Berkhout et. al

2. Dimitropoulos and Sorrell 
در مقاله حاضر جهت غلبه بر اين مشكل، از تجزيه قيمت انرزى (معرفى شده توسط

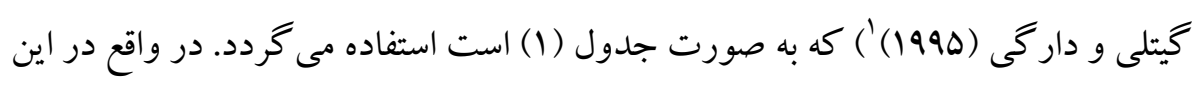

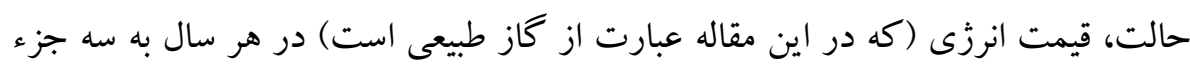

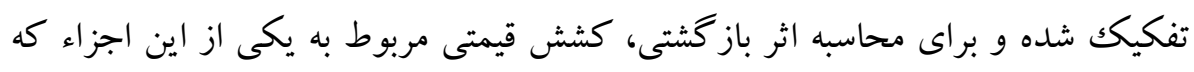

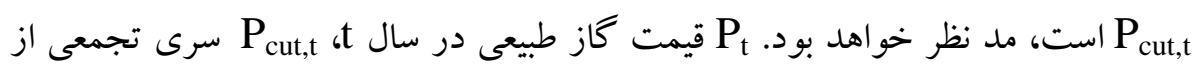

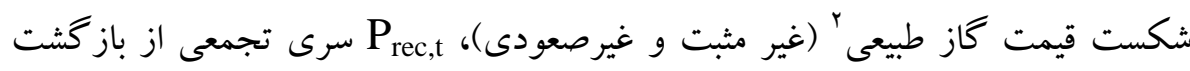

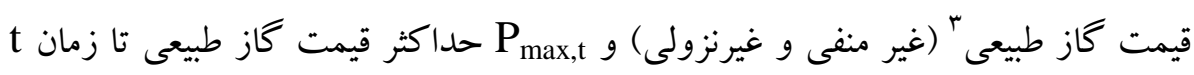

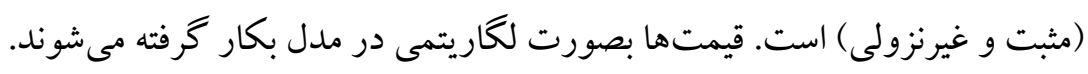

\begin{tabular}{c}
\hline$P_{t}=P_{\max , t}+P_{c u t, t}+P_{r e c, t}$ \\
\hline$P_{\text {max }, t}=\max \left\{P_{0}, P_{1}, \ldots, P_{t}\right\}$ \\
\hline$P_{c u t, t}=\sum_{i=0}^{t} \min \left\{0,\left(P_{\text {max }, i-1}-P_{i-1}\right)-\left(P_{\text {max }, i}-P_{i}\right)\right\}$ \\
\hline$P_{r e c, t}=\sum_{i=0}^{t} \max \left\{0,\left(P_{\text {max }, i-1}-P_{i-1}\right)-\left(P_{\max , i}-P_{i}\right)\right\}$ \\
\hline
\end{tabular}

منبع: گيتلى و دارگى، 1990

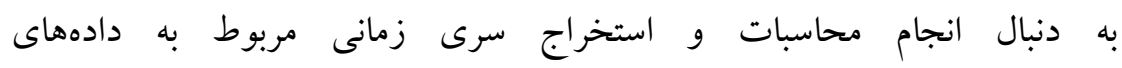

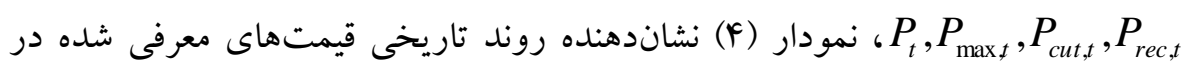
جدول (1) است. ملاحظه مىشود كه Pat,t همواره بايين محور افقى و Prec,t همواره بالاى محور افقى است.

1. Gately and Dargay

2. Cumulative Series of Price Cuts

3. Cumulative Series of Price Recoveries 


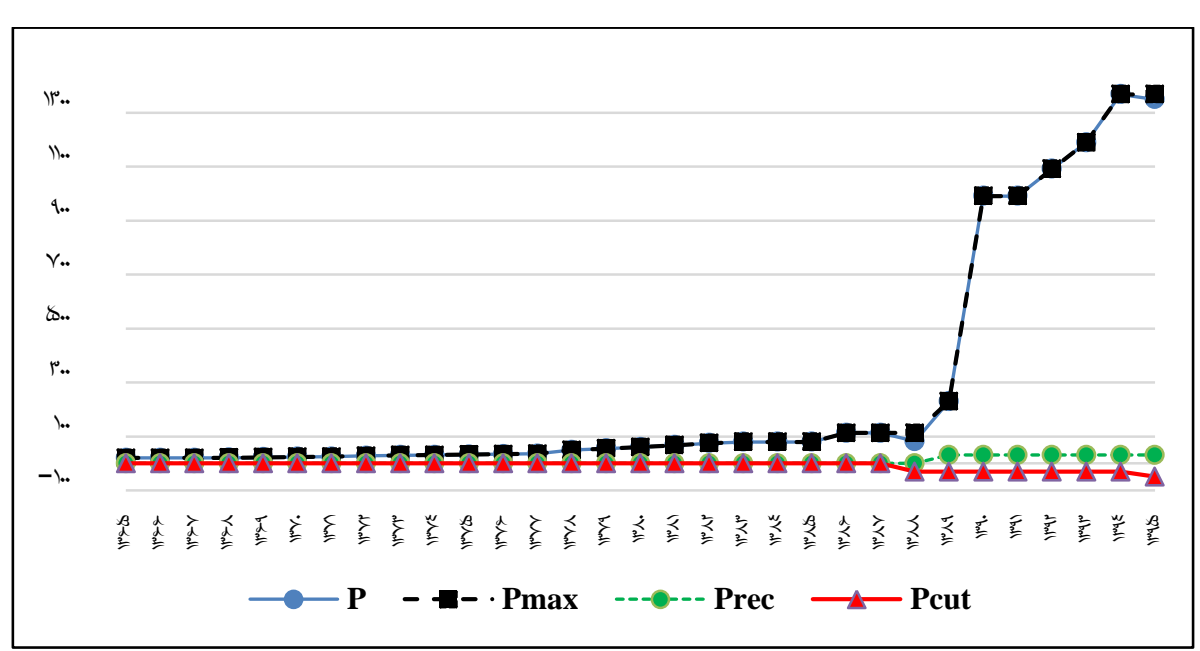

نمودار †. روند اجراى تجزيهشده قيمت كاز طبيعى (ريال/مترمكعب)

منبع: يافتهاى تحقيق

\section{†. بو بيشينه تحقيق}

مطالعات متعددى جه در داخل كثور و جهه در خارج از كثور در زمينه محاسبه اثرات

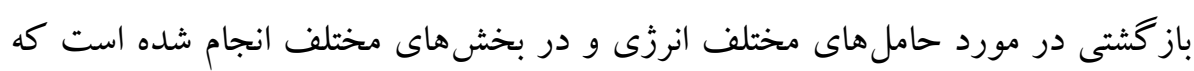

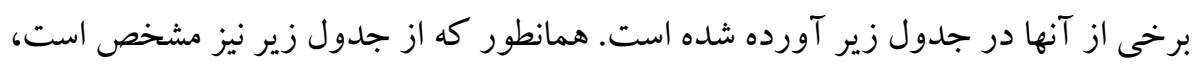

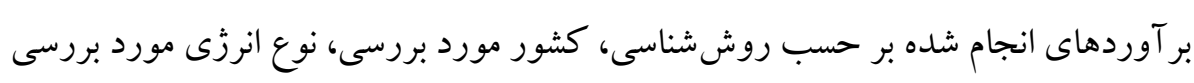
و غيره متفاوت است. 
برآورد اثر باز كثتى مستقيم ناشى از مصرف كاز طبيعى در ...

جدول r: مرورى بر ييشينه تحقيق

\begin{tabular}{|c|c|c|c|c|}
\hline نتيجه & روش & موضوع & كشور & محقق \\
\hline \multicolumn{5}{|c|}{ مطالعات خارجى } \\
\hline اثر باز گشتى بين ·r تا ·r & اقتصادسنجى & كرمايش محيط & اتريش & هاس و بيرمير (.... \\
\hline اثر باز گشتى هـ درصد & داده ستانده & مصرف انرزى در بخش & آمريكا & 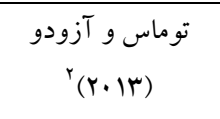 \\
\hline اثر باز گشتى VF درصد & اقتصادسنجى & مصرف انرزى در صنايع & جين & لين و لى (Y. r r r \\
\hline 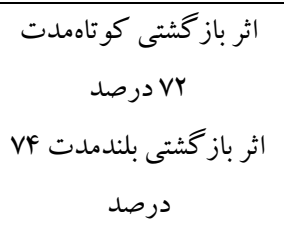 & بانل ديتا & خانو ارهاى شهرف برق در & جين & $\begin{array}{l}\text { وانق و همكاران } \\
{ }^{r}(Y \cdot \mid r)\end{array}$ \\
\hline اثر باز گشتى VI/ه درصد & حد آستانه & مصرف برق خانگى & جين & $\begin{array}{c}\text { زانق و همكاران } \\
{ }^{\circ}(Y .19)\end{array}$ \\
\hline اثر باز گشتى •Vدصد & CGE & انرزى & سطح جهانى & وى و ليو (Y.IV) \\
\hline اثر باز گشتى سل درصد & اقتصادسنجى & انرزى & التحاديه & $\begin{array}{c}\text { فرير كونزالس } \\
\text { v(r.lV) }\end{array}$ \\
\hline 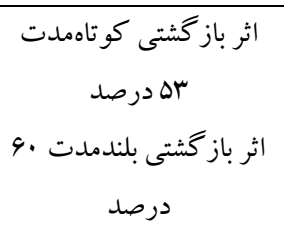 & اقتصادسنجى & تقاضاى گاز & فرانسه & 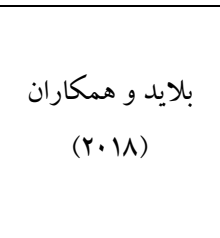 \\
\hline اثر باز گشتى .. إ٪وجود & اقتصادسنجى & برق و ساير سوختها & سوئد & $\begin{array}{c}\text { امجد وهمكاران } \\
\text { (Y. (Y) }\end{array}$ \\
\hline
\end{tabular}

1. Haas and Biermayr

2. Thomas and Azevedo (2013)

3. Lin and $\mathrm{Li}$ (2014)

4. Wang et. al. (2014)

5. Zhang et. al. (2016)

6. Wei and Liu (2017)

7. Freire Gonzalez, J. (2017) 


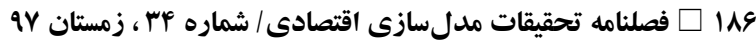

\begin{tabular}{|c|c|c|c|c|}
\hline نتيجه & 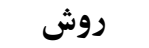 & موضوع & كشور & محقق \\
\hline \multicolumn{5}{|c|}{ مطالعات داخلى } \\
\hline اثر باز گشتى أ ا درصد & CGE & مصرف برق & ايران إن & 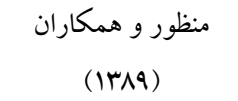 \\
\hline اثر باز گشتى 9 درصد & اقتصادسنجى & مصرف سوخت خودروها & ايران & 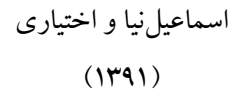 \\
\hline اثر باز گشتى rا درصد & CGE & مصرف بنزين & ايران إن & خوشكلام خسروشاهى، \\
\hline اثر باز گثشتى بنزين 9 درصد & اقتصادسنجى & حمل مصرف سوخت در & ايران إن & 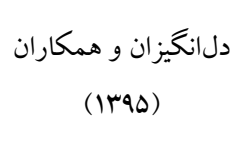 \\
\hline 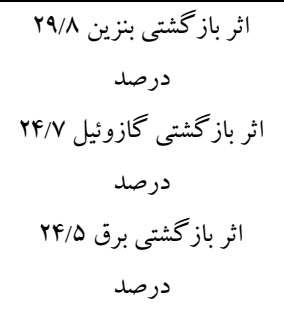 & CGE & مصرف بنزين، كازوئيل و & ايران إن & خسروشاهى (4) خلام \\
\hline اثر باز گشتى ايمدرصد & AIDS & مصرف برق خانكى & 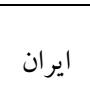 & 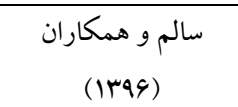 \\
\hline 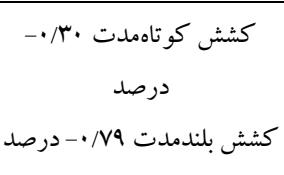 & اقتصادسنجى & صصرف گاز طبيعى در توليد فلزات & ايران & 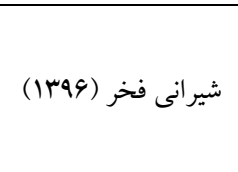 \\
\hline
\end{tabular}

منبع: يافتههاى تحقيق 
ه. دادها

در اين مقاله براى بر آورد اثر باز گشتى مستقيم ناشى از مصرف گاز طبيعى در بخش خانكى ايران از دادههاى سرى زمانى براى دوره هوس|-هذوس| استفاده مىشود. اصلىترين عوامل

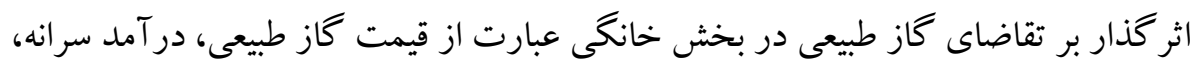

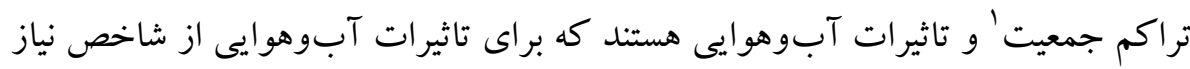

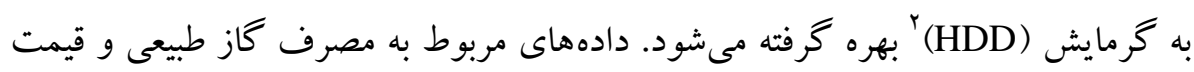

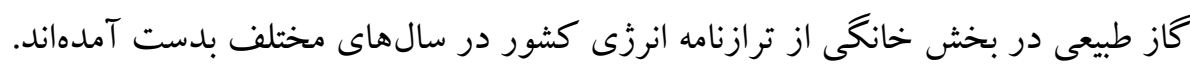

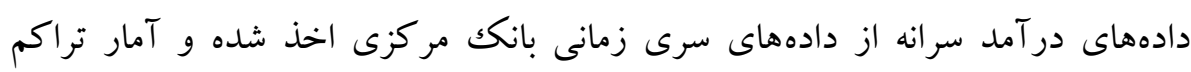

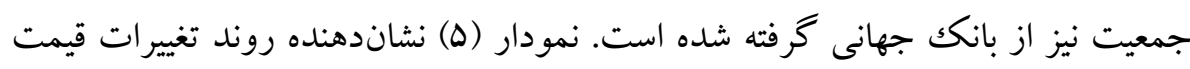
كاز طبيعى بوده و وجود روند در قيمت گاز طبيعى توجيه كننده بكار گيرى روش تجزيه قيمت ذكر شده در بخشهاى قبلى مقاله است. افزايش محسوس قيمت در سال . . مربوط به اجر اى قانون هدفمندسازى يارانها است.

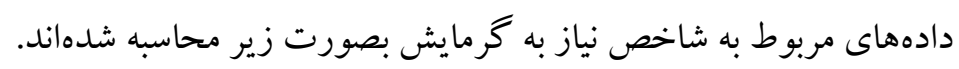

$H D D=\sum_{j=1}^{n d} \max \left(0, T_{H}-t_{j}\right) \quad, \quad T_{H}=18^{0} \mathrm{C}$

كه در آن nd تعداد روزها، th ميانخين دماى روز زامّ به درجه سانتى گراد و

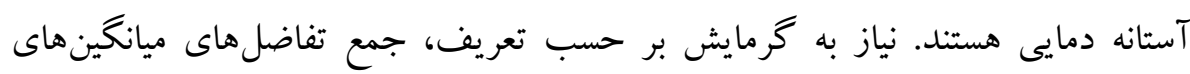
روزانه دما از آستانه معين است. دماى آستانه با توجه به شرايط، اعداد متفاوتى مى تو تواند

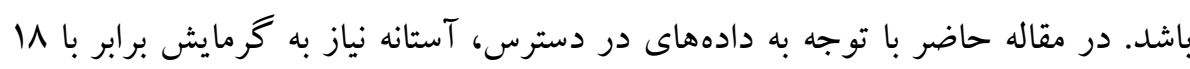

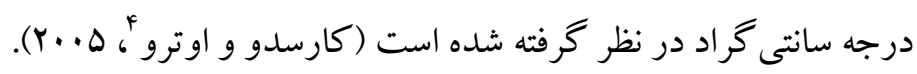

1. Population Density

2. Heating Degree Days (HDD)

r. دادهاى مربوط به متوسط دماى روزانه، از يور تال دانش تغييرات آب و هوايى (بانكك جهانى) به نشانى اينترنتى ا

4. Carcedo and Otero, 2005 


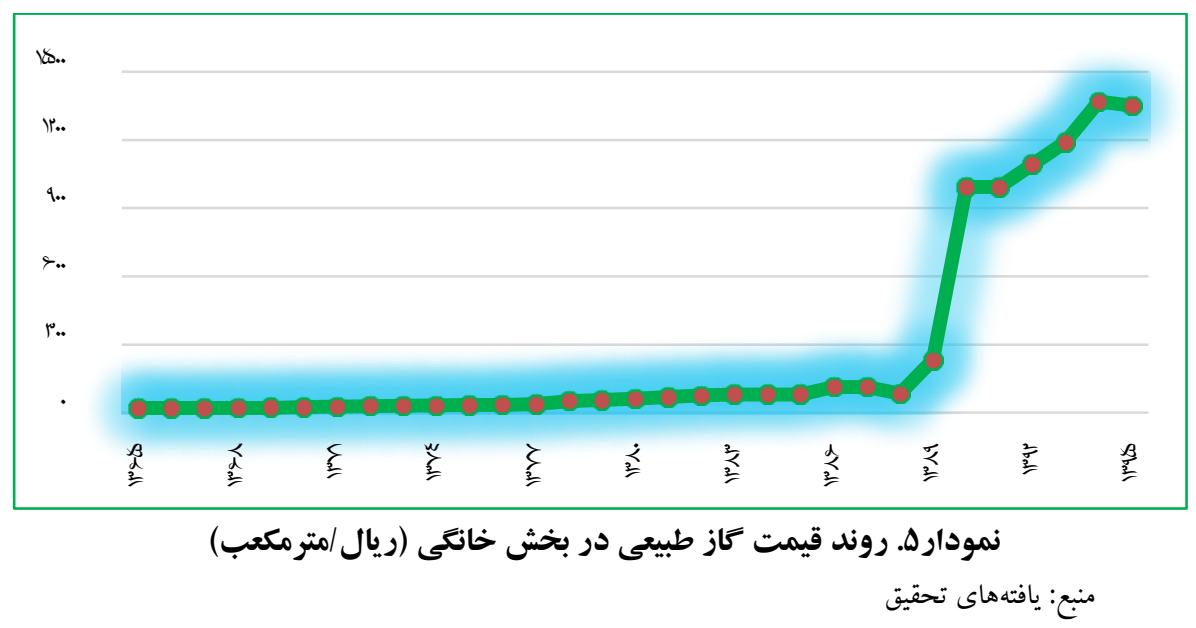

نمودار (9) روند تغييرات نياز به گرمايش را نشان مىدهد. همانطور كه ملاحظه مى شود، نياز به گرمايش در طول دوره مورد بررسى داراى روند كاهشى است.

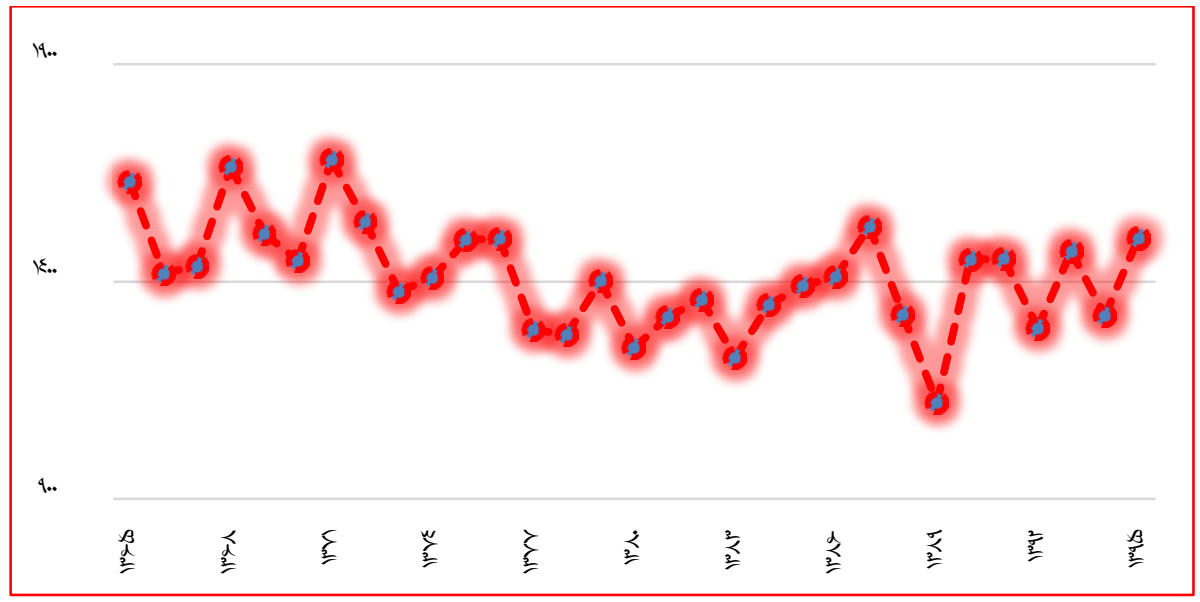

نمودار و. روند تغييرات نياز به كرمايش (درجه سانتى كراد)

منبع: يافتهاى تحقيق

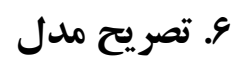

با توجه به آنجه در بخش سوم مقاله تبيين گرديد، براى اندازه گيرى اثر بازگتى

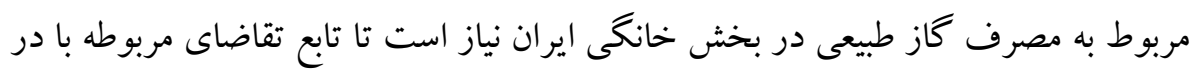


نظر گرفتن اين نكته كه قيمت گاز طبيعى به سه جزء تفكيك شده است، برآورد گرديده و

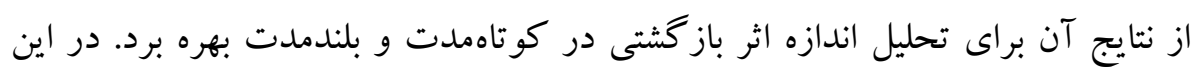

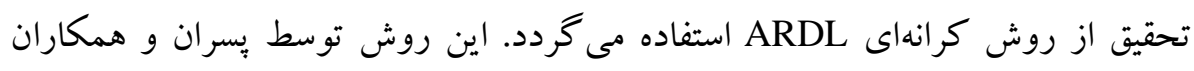

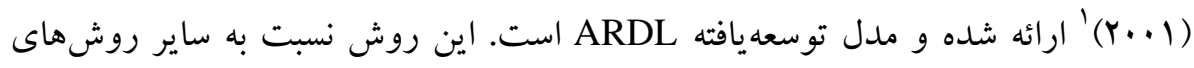

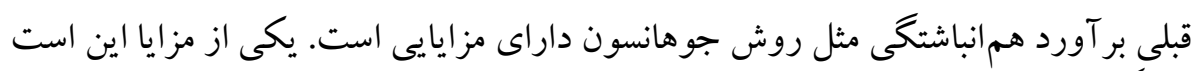

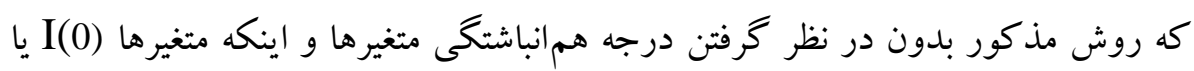

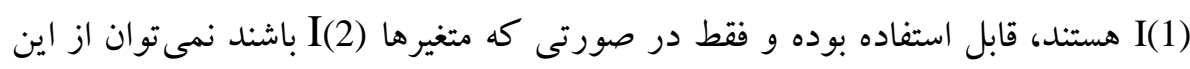

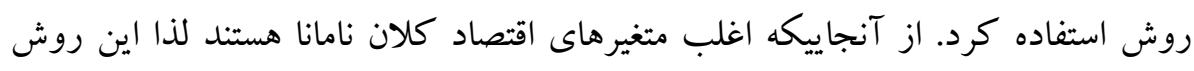
ابزار مناسبى محسوب مىشود. مزيت ديخر اين روش عبارت از كارايى بيشتر بكار گيرى

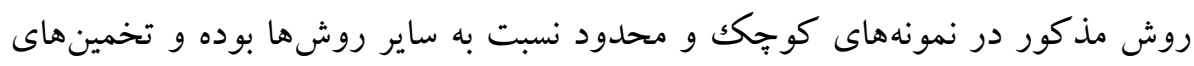

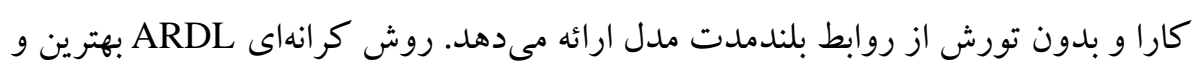

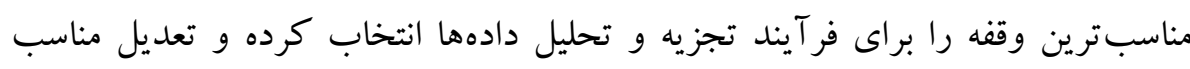
وقفهها در اين مدل باعث تصحيح مشكلات درونزايى و خودهمبستكى سريالى بطور

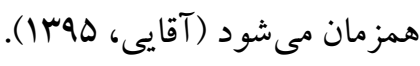

با توجه به دادههاى در دسترس و تئورىهاى اقتصادى، مدل بكار گرفته شده در اين

$$
\text { مقاله در قالب لخاريتمى - خطى بصورت رابطه (V) است. }
$$

$L G a s_{t}=\beta_{0}+\beta_{1} L P G D P_{t}+\beta_{2} L P_{\text {rec }, t}+\beta_{3} L P_{\text {cut }, t}+\beta_{4} L P_{\text {max }, t}+\beta_{5} L p o p_{t}+\beta_{6} L H D D_{t}+u_{t}$

در اين رابطه، همه متغيرها بصورت لخاريتمى بوده بطوريكه LGast لكاريتم مصرف كاز طبيعى بخش خانكى در سال t ، ،

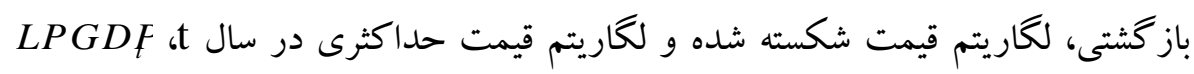
لكاريتم توليد ناخالص داخلى سرانه به قيمتهاى ثابت . . تراكم جمعيت در سال t و thDD لكاريتم نياز به گرمايش در سال t است. بارامترهاى

1. Pesaran et. al. (2001) 
به ، ....

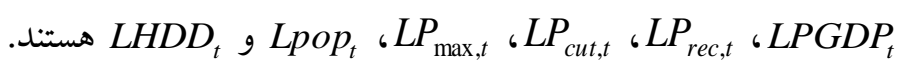

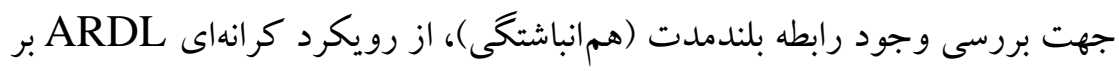

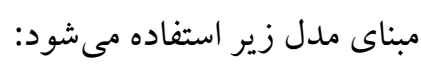

$\Delta L G a s_{t}=\alpha_{0}+\sum_{i=1}^{n-1} \alpha_{1 i} \Delta L G a s_{t-i}+\sum_{i=1}^{n-1} \alpha_{2 i} \Delta L P G D P_{t-i}+\sum_{i=1}^{n-1} \alpha_{3 i} \Delta L P_{r e c, t-i} \sum_{i=1}^{n-1} \alpha_{4 i} \Delta L P_{c u t, t-i}$

$+\sum_{i=1}^{n-1} \alpha_{5 i} \Delta L P_{\max , t-i}+\sum_{i=1}^{n-1} \alpha_{6 i} \Delta L \operatorname{Lop}_{t-i}+\sum_{i=1}^{n-1} \alpha_{7 i} \Delta L H D D_{t-i}+\beta_{1} L G A S_{t-1}+\beta_{2} L P G D P_{t-1}$

$+\beta_{3} L P_{\text {rec }, t-1}+\beta_{4} L P_{\text {cut } t,-1}+\beta_{5} L P_{\max , t-1}+\beta_{6} L p o p_{t-1}+\beta_{7} L H D D_{t-1}+\varepsilon_{t}$

وجود رابطه همانباشتخى بين متغيرها در بلندمدت بواسطه آماره F كه داراى توزيع

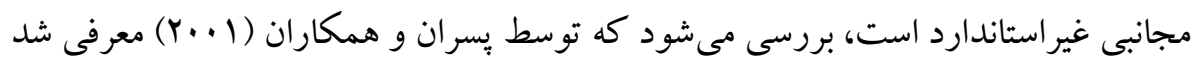

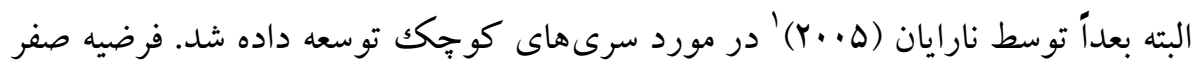

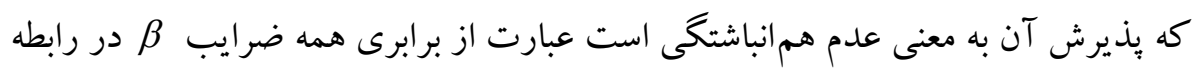

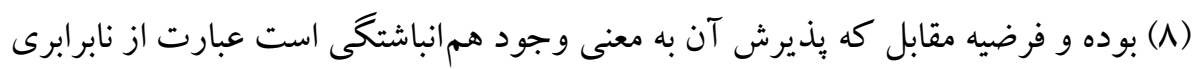

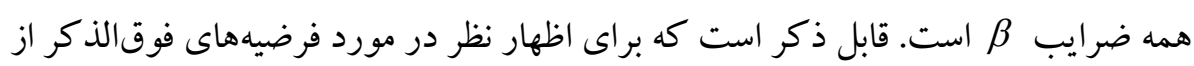

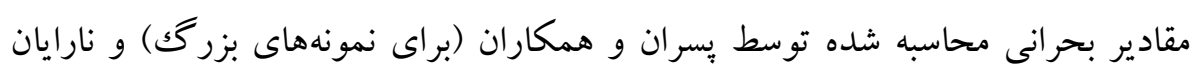

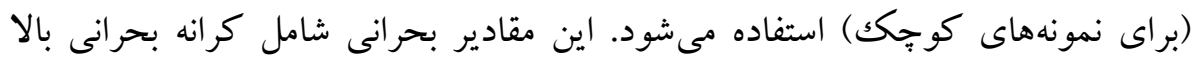
(UCB) هم انباشتخى مورد استفاده قرار مى گيرند.

1. Narayan (2005)

2. Upper Critical Bound

3. Lower Critical Bound 
در صورتيكه رابطه همانباشتخى بين متغيرها وجود داشته باشد آنگاه مدل تصحيح

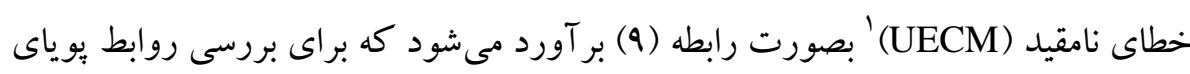
بلندمدت و كو تاهمدت بين متغيرها مورد استفاده قرار مى كيرد. $\Delta \operatorname{LGas}_{t}=\alpha_{0}+\sum_{i=1}^{n-1} \alpha_{1 i} \Delta L G a s_{t-i}+\sum_{i=1}^{n-1} \alpha_{2 i} \Delta L P G D P_{t-i}+\sum_{i=1}^{n-1} \alpha_{3 i} \Delta L P_{\text {rec }, t-i} \sum_{i=1}^{n-1} \alpha_{4 i} \Delta L P_{\text {cut }, t-i}$ $+\sum_{i=1}^{n-1} \alpha_{5 i} \Delta L P_{\max , t-i}+\sum_{i=1}^{n-1} \alpha_{6 i} \Delta L p o p_{t-i}+\sum_{i=1}^{n-1} \alpha_{7 i} \Delta L H D D_{t-i}+\xi Z_{t-1}+v_{t}$

در اين رابطه، بلندمدت بعد از شوكى كو تاهمدت است.

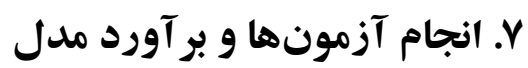

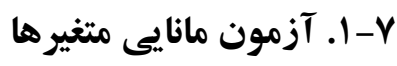

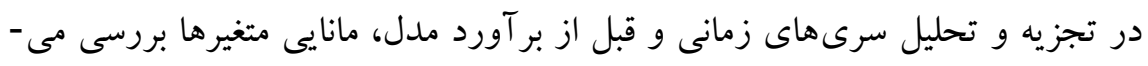
شود. در بر آورد مدل به روش كرانهاى ARDL فرض اساسى اين است كه متغيرهاى مورد بررسى هم انباشته از مرتبه صفر يا مرتبه يكك و يا همانباشته از مرتبه صفر و يكك هستند و و ورد

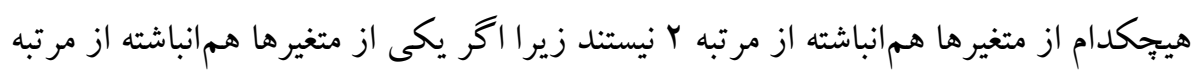

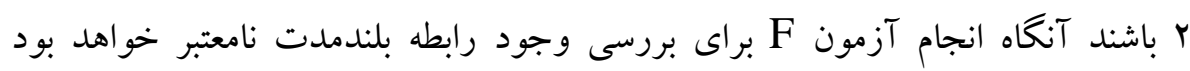

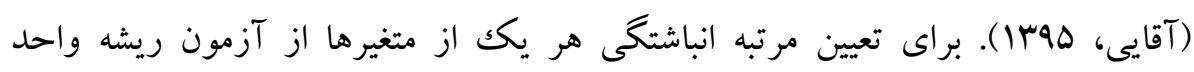

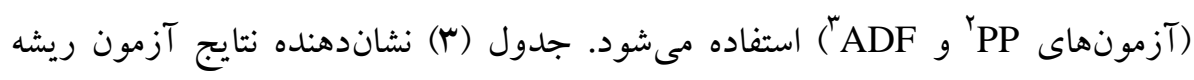
واحد بوده و ملاحظه مى شود كه برخى متغيرها در سطح مانا بوده و برخى ديخر در سطح

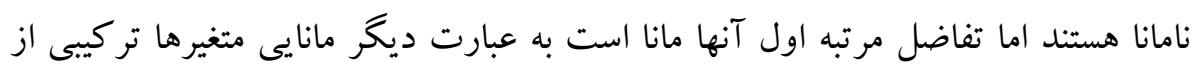

1. Unrestricted Error Correction Model

2. Phillips-Perron (PP)

3. Augmented Dickey-Fuller (ADF) 


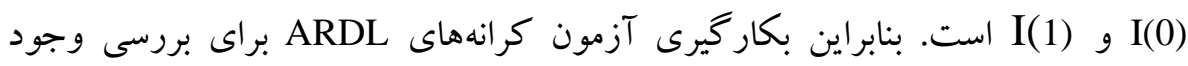
هم انباشتخى بين متغيرهاى مدل توجيه يذير است.

\begin{tabular}{|c|c|c|c|c|c|c|c|}
\hline \multicolumn{8}{|c|}{ جدول r. آزمون ريشه واحد } \\
\hline LHDD & Lpop & $L P G D P$ & $L P_{\max }$ & $L P_{\text {cut }}$ & $L P_{\text {rec }}$ & LGas & شرح \\
\hline$-\kappa / \Lambda$. & $-r / 90$ & $-1 / \pi r$ & $-1 / \cdot 1$ &.$- / 90$ &.$- / 91$ & $-1 / 14$ & 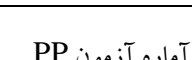 \\
\hline$(\% / . \cdot)$ & $(\cdot / *)$ & $(. / 90)$ & $(\cdot / \Lambda r)$ & $(. / 91)$ & $(\cdot \mathrm{NQ})$ & $(\cdot / 9 r)$ & ( \\
\hline $\mathrm{I}(\cdot)$ & $\mathrm{I}(\cdot)$ & $\mathrm{I}(1)$ & $\mathrm{I}(1)$ & $\mathrm{I}(1)$ & $\mathrm{I}(1)$ & $\mathrm{I}(1)$ & درجه مانايى \\
\hline$-4 / 4$. & $-r / r \Lambda$ & $-1 / \pi 1$ & -.199 & $-\cdot / \wedge \mu$ &.$- / v \Delta$ & $-1 / \cdot 1$ & \\
\hline$(\cdot / \cdot r)$ & $(\cdot / r)$ & $(\cdot / q \Delta)$ & $(\cdot N F)$ & $(\cdot / 9 V)$ & $(\cdot / \wedge 9)$ & $(\cdot / 9 \Delta)$ & آماره آزمون ADF \\
\hline $\mathrm{I}(\cdot)$ & $\mathrm{I}(\cdot)$ & $\mathrm{I}(1)$ & $\mathrm{I}(1)$ & $\mathrm{I}(1)$ & $\mathrm{I}(1)$ & $\mathrm{I}(1)$ & درجه مانايى \\
\hline
\end{tabular}

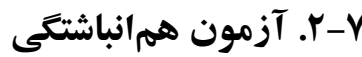

جدول (F) نشاندهنده نتايج مربوط به آزمون هم انباشتخى بين متغيرها بوده و مبتنى بر روش

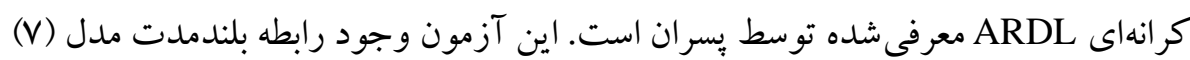

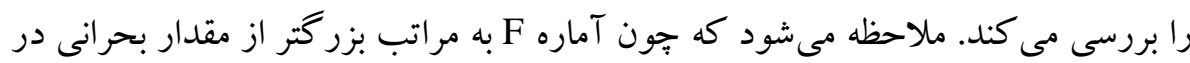
كليه سطوح احتمال خاصه سطح احتمال ا درصد است لذا فرضيه صفر مبنى بر عدم وجود مدود

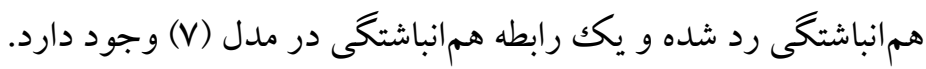

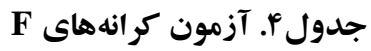

\begin{tabular}{|c|c|c|c|c|}
\hline $\mathbf{I}(1)$ & $\mathbf{I}(\cdot)$ & سطح معنىدارى & مقدار آماره & آماره آزمون \\
\hline Y/AF & $1 / 99$ & $\% 1$. & $1 \% / r$. & T Tاره F \\
\hline$r / Y \wedge$ & $Y / Y V$ & $\%$ & 4 & تعداد متغيرهاى مستقل \\
\hline r/99 & $\mathrm{r} / \mathrm{M}$ & $\% 1$ & & \\
\hline
\end{tabular}

منبع: يافتهاى يُوهش 


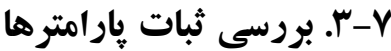

براى اجتناب از تورش مربوط به بىثباتى پارامترها، از آزمونهاى معرفى شده توسط يسران (199VV) براى بررسى ثبات يارامترها در كوتاهدت و بلندمدت استفاده مىشود. براى اين منظور از دو آزمون يسماند تجمعى (CUSUM)' و مجذور يسماند تجمعى (CUSUMQ) بهره كرفته شده و نتايج مربوط به اين آزمونها در قالب نمودارهاى (V) و (N) آورده شده

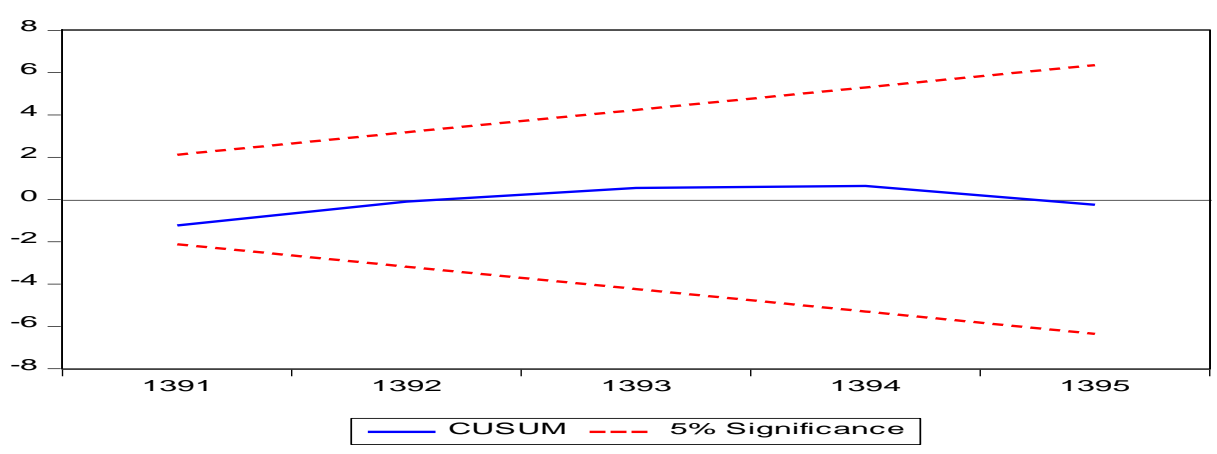

CUSUM نمودار \. نتايج آزمون

منبع: يافتهاى تحقيق

ملاحظه مى گردد كه نمودارهاى CUSUM و CUSUMQ در محدوده كرانههاى بحرانى در سطح احتمال لهدرصد بوده و لذا ثبات يارامترهاى مدل ARDL مورد تاييد

1. Cumulative Sum of Recursive Residual (CUSAM)

2. Cumulative Sum of Squares of Recursive Residuals (CUSUMQ) 
Q I q

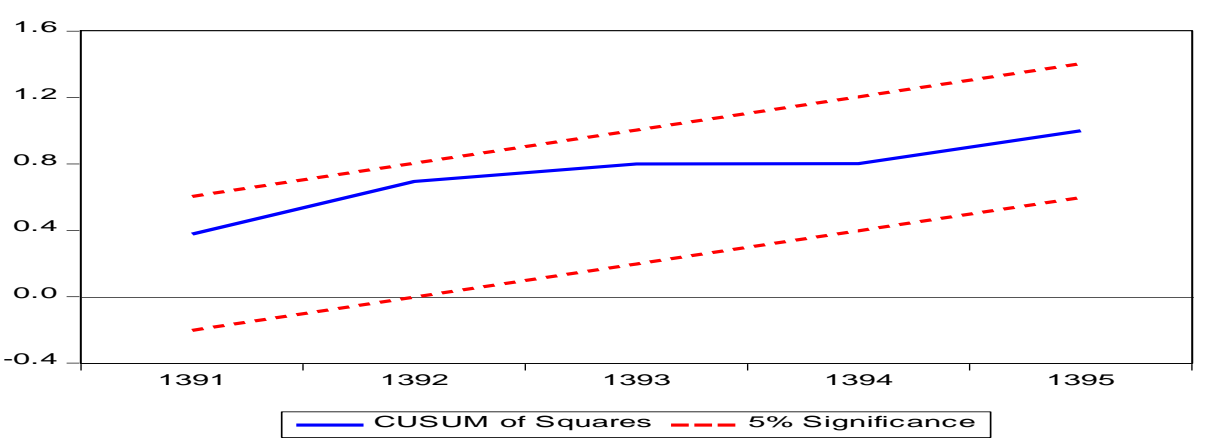

CUSUMQ نموداري. نتايج آزمون

منبع: يافتهاى تحقيق

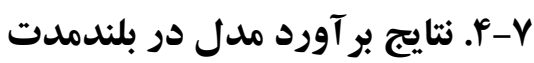

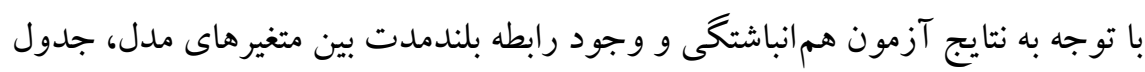

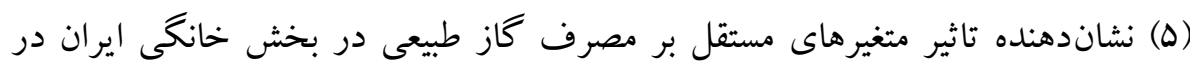

بلندمدت است.

\begin{tabular}{|c|c|c|c|c|}
\hline سطح احتمال & Tاره & انحراف استاندارد & ضريب & متغير \\
\hline 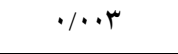 & $r / .9$ & $\cdot / r \cdot 1$ & 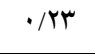 & LPGDP \\
\hline.$/ \cdot 1$ & $q / 4 \Delta$ &.$/$ /QF & $1 / 1 \wedge$ & $L P_{r e c}$ \\
\hline$\cdot / \cdot \lambda r$ & $-1 / 19$ & $\cdot / Y \wedge 9$ & ${ }^{*}-\cdot / \mathrm{VA}$ & $L P_{c u t}$ \\
\hline.$/ . r$. & $-F / V \mu$ & . / IFY & $-\cdot 194$ & $L P_{\max }$ \\
\hline$\cdot|\cdot 4|$ & $F / 9 V$ & $\cdot$ • rar & $1 / F r$ & Lpop \\
\hline$\cdot / \cdot \Delta$ & $r / 11$ & $\cdot / 191$ & $\cdot / 09$ & $L H D D$ \\
\hline
\end{tabular}

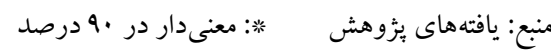

ضرايب بر آورد شده براى متغيرها ضمن اينكه به لحاظ آمارى معنى دارد داردار هستند بلكه

نشان مىدهند كه افزايش در متغيرهاى توليد ناخالص داخلى سرانه، تراكم جمعيت و نياز به كرمايش باعث افزايش در مصرف گاز طبيعى خانكى مىشوند. جِنانجه توليد ناخالص

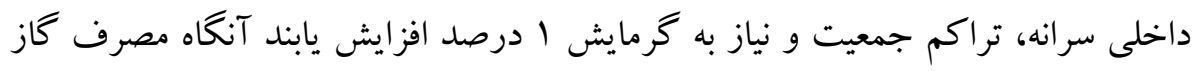

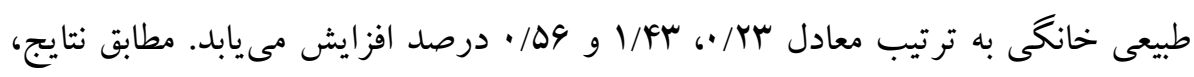


افت قيمت گاز طبيعى (LP $)$ در ايران تاثير منفى و معنىدار بر مصرف گاز خانگى كشور

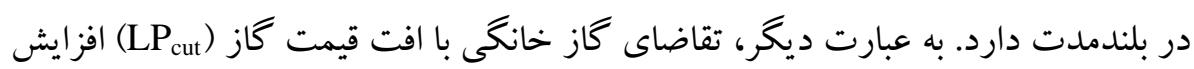

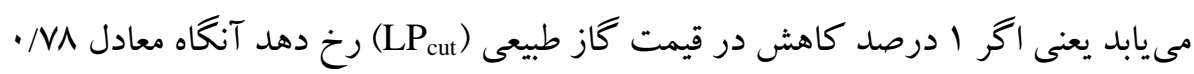

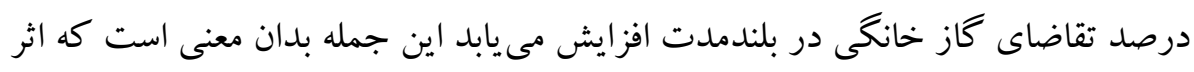

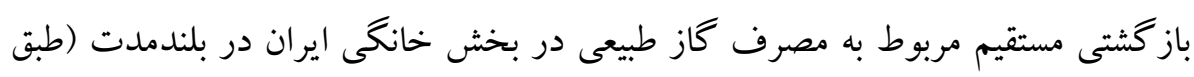

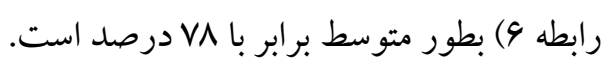

- Y-ه. نتايج بر آورد مدل در كوتاهمدت

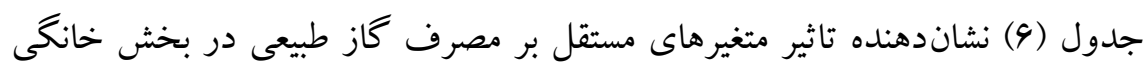
ايران در كوتاهمدت است. جدول \&: نتايج مدل تصحيح خطاى ARDL مر كوتاه

\begin{tabular}{|c|c|c|c|c|}
\hline سطح احتمال & Tاره & انحراف استاندارد & ضريب & متغير \\
\hline$\cdot / \cdot$ & $r / 19$ & . /AY &.$/ 10$ & $\triangle L P G D P$ \\
\hline.$/ \cdot r$ & r/Ar & $\cdot / 419$ & $1 / 1 r$ & $\Delta L P_{r e c}$ \\
\hline$\cdot / \cdot v$ & $-r / I r$ & $\cdot /$ TAF & $=.199$ & $\Delta L P_{c u t}$ \\
\hline.$/ \cdot r$ & $-r / 9 r$ &.$/ \mathrm{kT}$ & $-\cdot / \Delta V$ & $\Delta L P_{\max }$ \\
\hline.$/ . \Delta$ & $r / 99$ & $\cdot / 491$ & $1 / F 1$ & $\Delta L p o p$ \\
\hline 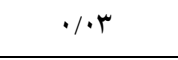 & $r / 10$ & $\cdot / N \Delta$ & $\cdot / \Delta r$ & $\triangle L H D D$ \\
\hline.$/ \cdot 1$ & $-F / 19$ &.$/ Y Y A$ & $-\cdot / 94$ & $E C T(-1)$ \\
\hline
\end{tabular}

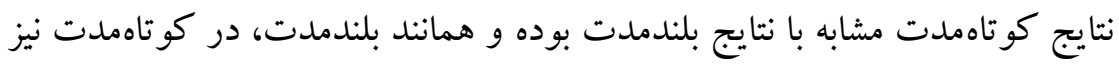
تاثير تغييرات در قيمت گاز طبيعى (LP معنىدار است. بنابراين اكر ا درصد كاهش در قيمت گاز طبيعى (LP) مصرف كاز طبيعى خانگى در كوتاهمدت معادل 199• درصد افزايش مى يابد به عبارت

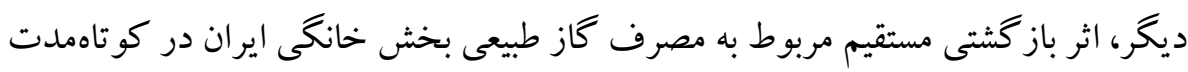
(طبق رابطه 9) بطور متوسط برابر با 99 درصد است مرئ. 
ضريب مربوط به متغير ECT(-1) كه نشاندهنده سرعت تعديل است، برابر با

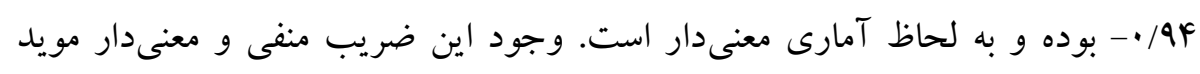

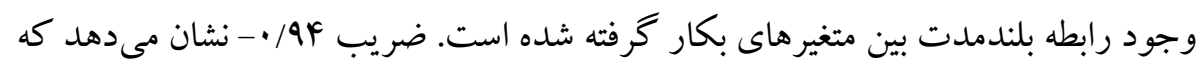

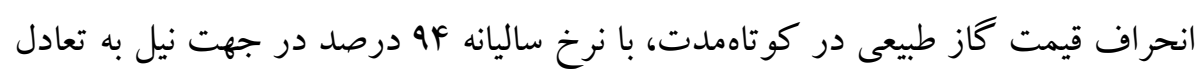
بلندمدت اصلاح مى شود. يافتهاى تحقيق مويد وجود اثر باز گشتى مستقيم ناشى از مصرف كاز طبود طبيعى در بخش خانكى ايران است بطوريكه طبق ضريب بر آورد شده در كوتاهمدت،

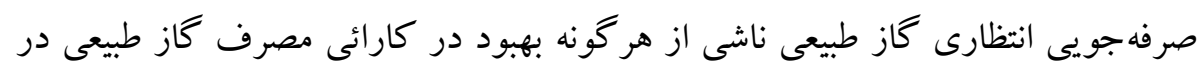

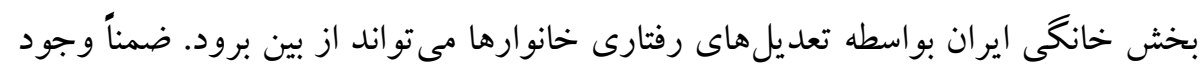

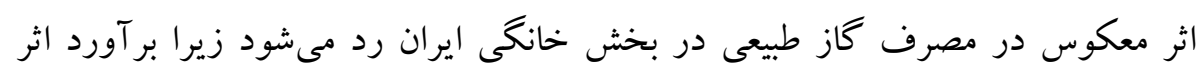

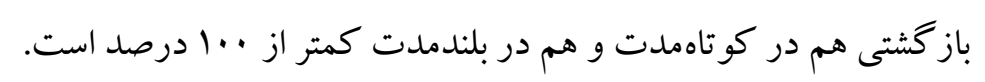




\section{^. نتيجه كيرى و توصيه سياستى}

با توجه به نقش مهمى كه تقاضاى مصرفى كاز طبيعى در بخش خوصيه خانكى ايران دارد، مقاله

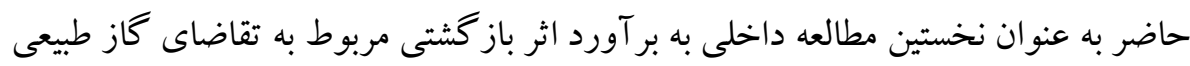

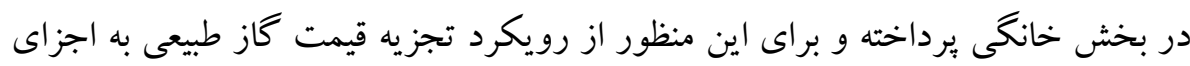

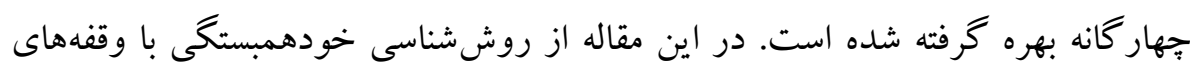

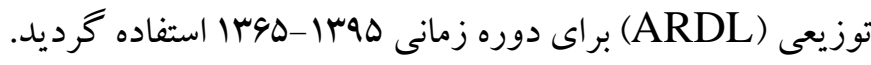

نتايج مقاله حاكى از آن هستند كه اثر باز گشتى ناشى از مصرف گاز زاز طبيعى در بخش

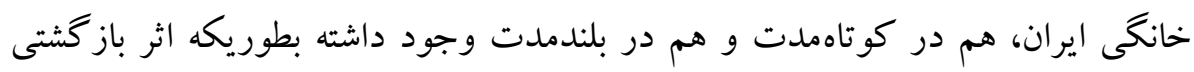

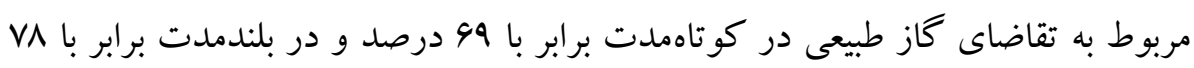

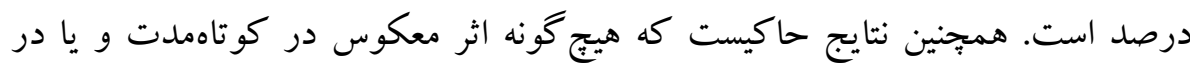

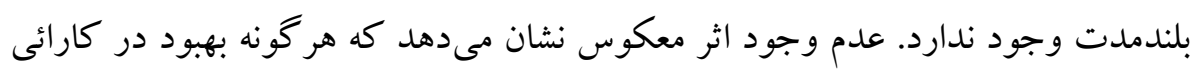

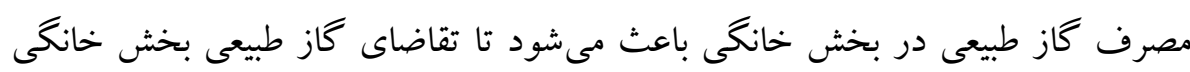

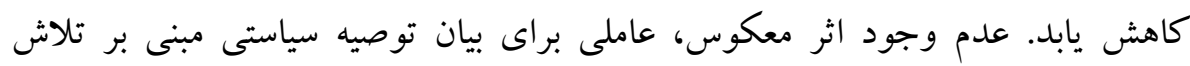
سياست گذاران جهت بهبود كارائى مصرف گاز طابل طبيعى است.

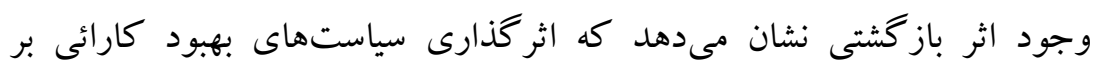
مصرف گاز طبيعى، كمتر از آن ميزانى است كه مورد انتظار سياست گذذاران بوده است. وجود اثر باز گشتى 99 درصد در كوتاهمدت نشان مىدهد كه تنها اس درصد از إنى

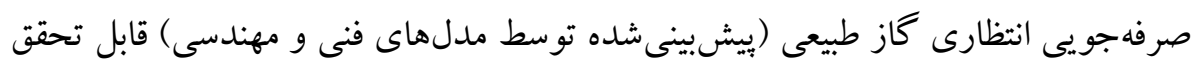

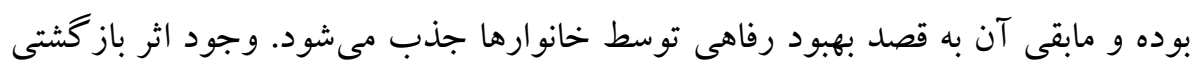

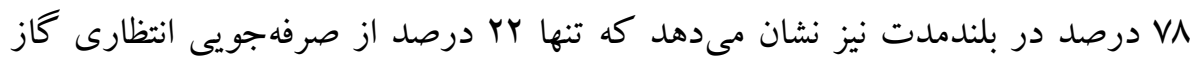
طبيعى قابل تحقق بوده و مابقى آن توسط خانوارها جذب مىشود. بنابراين بيشينى و و

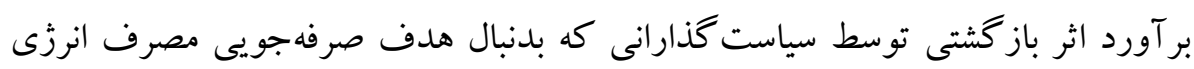
هستند، بسيار ضرورى بوده و بهعنوان توصيه سياستى قابل بيان است. 
- Amjadi G., Lundgren T., and Persson L. (2018). The rebound Effect in Swedish Industry. Energy Economics. 71, 140-148.

- Aghaei M. (2016). Investigating the relationship between causality between energy consumption and economic growth by energy carriers and different economic sectors: Application of ARDL. Quarterly Journal of Energy Economics, 49, 103-161.

- Annual Energy Outlook 2017 (with Projections to 2050), EIA.

- Belaid F., Bakaloglou S., and Roubaud D. (2018). Direct rebound effect of residential gas demand: Empirical evidence from France. Energy Policy, 115, 23-31.

- Berkhout P., Muskens J., and Velthuijsen J. (2000). Defining the Rebound Effect. Energy Policy, 28, 425-432.

- Carcedo J., and Otero J. (2005). Modelling the non-linear response of Spanish electricity demand to temperature variations. Energy Economics, 27(3), 477-494.

- Dargay J., and Gately D. (1995). The imperfect price reversibility of nontransport oil demand in the OECD. Energy Economics, 17(1), 59-71.

- Delangizan S., Khanzadi a., and Heidarian M. (2017). Estimation and analysis of direct rebound effects due to improved fuel efficiency in Iran's road transport sector. Quarterly Journal of Applied Economic Studies of Iran, 6(21), 149-172.

- Energy Balance, Many Years.

- Esmaeilnia A., and Ekhtyari S. (2012). Investigating the Rebound Effects of Improving Vehicle Efficiency on Fuel Consumption. Quarterly Journal of Energy Economics, 34, 185-213.

- Freire-Gonzalez J. (2017). Evidence of direct and indirect rebound effect in households in EU-27 countries. Energy Policy, 102, 270-276.

- Greening, L., Greene, D., and Difiglio, C. (2000). Energy Efficiency and Consumption - the Rebound Effect - A Survey. Energy Policy, 28, 389401.

- Haas, R., and Biermayr, P. (2000). The rebound effect for space heating empirical evidence from Austria, Energy Policy, 28, 403-410.

- http://sdwebx.worldbank.org/climateportal/

- Khoshkalam Khosroshahi M., Jahangard M., and Abedian M. (2015). Improving the efficiency of gasoline consumption and its rebound effects in various economic activities. Quarterly Journal of Energy Economics, 44, 37-63.

- Khoshkalam Khosroshahi M. (2017). Investigating the economic effects of using non-tariff policies on the use of energy carriers. Journal of Economic Modeling Research, 29, 37-72. 
- Lin, B., and Li, J. (2014). The rebound effect for heavy industry: Empirical evidence from China. Energy Policy, 74(C), 589-599.

- Lu, Y., Liu, Y. and Zhou, M. (2016). Rebound Effect of Improved Energy Efficiency for Different Energy Types: A General Equilibrium Analysis for China. CAMA Working Paper 38/2016.

- Manzoor D., Aghababaei M., and Hagigi I. (2010). Analyzing the Rebound Effects Caused by Improving Efficiency in Electricity Consumption in Iran: Computable General Equilibrium Model. Quarterly Journal of Energy Economics, 8(28), 1-23.

- Salem A., and Akaberi M. (2017). Estimating the Direct Rebound Effect of Improving Power Consumption Efficiency in the Household Section of Urban Areas of Iran. Iranian Energy Economics Researches, 6(22), 4574.

- Shrani Z. (2017). Estimation of price and production stretch of natural gas demand function in the sub-sectors of Iran's basic metals production industries. Journal of Economic Modeling Research, 8(30), 170-218.

- Sorrell, S. (2007). UKERC Review of Evidence for the Rebound Effect. UKERC.

- Sorrell S., Dimitropoulos J. and Sommerville, M. (2009). Empirical Estimates of the Direct Rebound Effect: A Review. Energy Policy, 37, 1356-1371.

- Sorrell, S. and Dimitropoulos, J. (2006). The rebound effect: microeconomic definitions, extensions and limitations. In: Proceedings of the 29th IAEE International Conference. Potsdam, Germany.

- Time Series data, Central Bank of Iran

- Thomas, B. and Azevedo, I. (2013). Estimating direct and indirect rebound effects for U.S. households with input-output analysis. Part 2: Simulation. Ecological Economics, 86, 188-198.

- Wang Z, Lu M and Wand, J. (2014). Direct rebound effect on urban residential electricity use: An empirical study in China. Renewable and Sustainable Energy Reviews, 30, 124-132.

- Wei, T. and Liu, Y. (2017). Estimation of global rebound effect caused by energy efficiency improvement. Energy Economics, 66, 27-34.

- https://data.worldbank.org/indicator/EN.POP.DNST

- Zhang, Y. and Peng, H. (2016). Measuring the direct rebound effect of China's residential electricity consumption. Energy Procedia, 104, $305-$ 310.

- Zhang, M, Song, Y, Li, P. and Li, H. (2016). Study on affecting factors of residential energy consumption in urban and rural Jiangsu. Renewable and Sustainable Energy Reviews, 53, 330-337. 


\title{
Estimating the Direct Rebound Effect of Natural Gas Consumption in the Iranian Residential Sector with the Asymmetry of Gas Price Changes
}

\author{
Musa Khoshkalam Khosroshahi ${ }^{1}$
}

Received: 2017/05/09 Accepted: 2018/11/26

\begin{abstract}
Considering that the improvement of energy efficiency and the resulting rebound effect in the literature of energy economics is very important, hence the present paper uses the ARDL approach to estimate the direct rebound effect of the natural gas consumption in the residential sector in Iran. For this purpose, data from the period of 1986-2016 and the methodology based on the estimation of natural gas demand elasticity according to decomposed prices have been used. The results show that, firstly, the direct rebound effect of the natural gas consumption in the residential sector exists and, as a result, energy savings due to improved energy efficiency will be less than expected. Secondly, the direct rebound effect of natural gas demand in the short run is $69 \%$ and in the long run is $78 \%$. Also, the findings indicate that there is no backfire effect of residential consumption of natural gas. Therefore, it is recommended to apply policies to improve the efficiency of natural gas consumption in Iran's domestic sector.
\end{abstract}

Keywords: Natural Gas, Rebound Effect, Price Decomposition, Residential Sector.

JEL Classification: C13, D61, L95, Q42. 